\title{
ENGINEERING FEATURES OF THE SAN FERNANDO EARTHOUAKE
}

\author{
By the Earthquake Engineering Research Laboratory, California Institute of Technology."
}

This paper was received for publication in May 1971.

Apologies are extended to the authors for the delays in publication.

At 6 a.m. Tuesday, February 9, 1971, the strongest earthquake to strike metropolitan Los Angeles in this century occurred in the northern San Fernando Valley. The magnitude 6.6 earthquake was not a large earthquake in seismological sense; earthquakes of this magnitude occur at an average rate of $30-40$ per year on the earth, and on the average of about once every four years in the southern California area. From the engineering point of view, however, the earthquake was a very large and important one bccause it was located at the edge of a densely populated urban area and the region of heaviest ground motion contained an unusually large number of such critical installations as hospitals, dams, electrical switching and converter stations, and freeway interchanges. Some 400,000 people were subjected to very strong ground shaking, and an additional 2,000,000 to moderately strong motion. Furthermore, the particular type of overthrust faulting that occurred resulted in a release of earthquake energy at an unusually shallow depth. Many of the heavily damaged facilities were virtually right on top of the earthquake and were subjected to severe shaking.

The estimated cost of the damage caused by the earthquake is in the vicinity of onebillion dollars.

\section{Summary of the Effects of the Earthquake}

Figure 1 shows the location of some of the major structures and facilities referred to in this section. The major loss of life occurred at the Veteran's Administration Hospital in Sylmar where a concrete frame, tile-wall, pre-earthquake code, hospital building collapsed, killing 44. Another 11 were killed elsewhere, including two crushed by a collapsed freeway overpass, and an additional 9 were reported to have died from heart attacks. Four major facilities in the

* The text of this paper was prepared by Paul $C$. Jennings (1) and originally presented in Engineering and Science, a journal published by the California Institute of Technology. The photographs were assembled and captioned by John $\mathrm{H}$. Wood $(2)$. Much of the information was obtained from other members of the Earthquake Engineering Research Laboratory. Contributing personnel include G. W. Housner, D. E. Hudson, R. F. Scott, W. D. Iwan, M. D. Trifunac, G. Frazier and A. G. Brady.

(1) Associate Professor of Applied Mechanics, California Institute of Technology.

(2) Graduate Student, California Institute of Technology. At present on study leave from the New Zealand Ministry of Works. central region of the shock suffered severo damage: the new olive View Hospital (initial cost $\$ 27$ miliion): the Sylmar Converter Station of the Pacific Intertie (this large electrical switching and rectifying station had an initial cost of about $\$ 110$ million); the Metropolitan water District's new, large underground reservoir; and two earth dams at the van Noman reservoir site (constructed 1915-1928).

There was also severe damage from ground movements to the six and one-half million dollar San Fernando Juvenile facility and vibrational and ground-movement damage to numerous one-w and two-story industrial and commercial buildings in the San Fernando Valley. Some buildings in the eight to fifteen-story range in North Hollywood ( 16 miles from the epicenter) suffered structural damage. In addition to the Veterans Hospital at Sylmar and the Olive View Hospital, the Pacoima Lutheran Hospital, the Holy Cross Hospital and the nearby Indian Hills Medical Center (an office building) all received serious structural damage. The most severe industrial damage occurred near Newhall where a glass factory suffered approximately $\$ 10$ million damage. Nonstructural damage, including broken glass, fallen light fixtures and ceilings, and plaster cracking occurred throughout the San Fernando Valley and also in the adjoining areas of Glendale, Pasadena, Los Angeles (25 miles from the epicenter) and to the north at Newhall and saugus.

An estimated \$15 million damage was done to bridges and overpass structures on the Golden State, Foothill, San Diego and Antelope Valley freeways. Particularly hard hit were the interchange between the Golden state and Antelope Valley freeways and the interchange between the Foothill freeway and the Golden state freeway. Bridges on the Antelope Valley and Foothill freeways in the epicentral area also received serious damage.

Permanent ground displacements caused extensive disruption to underground utilities in parts of the San Fernando Valley, especially where surface faulting occurred. Gas lines were ruptured in several areas and water and sewer lines also were fractured affecting service to thousands of homes. Telephone service was lost to ten to twenty thousand customers in the epicentral area from approximately 4.5 million dollars damage to General Telephone's central facility in Sylmax. Emergency communications were hampered by a power outage at police headquarters and by destruction of the radio facility at the veteran's Hospital.

The faulting and the ground movement, combined with the shaking, damaged thousands of 
homes and hundreds were damaged to the point where they no longer could be occupied. Chimney damage was the most common vibrational damage and occurred as far away as Pasadena.

Old weak buildings in downtown San Fernando and as far away as Pasadena ( 22 miles from the epicenter), Los Angeles (25 miles from the epicenter) and Santa Ana (50 miles from the epicenter) suffered significant damage, usually in the form of falling masonry. Two people were killed by failure of old buildings in downtown Ios Angeles. Caltech's oldest building, Throop Hall, suffered extensive cracking to the nonstructural tile filler walls and to the exterior facing. Although no structural damage occurred in this earthquake. Throop Hall falls well below modern standards, and its eventual fate has not yet been decided.

Although the earthquake damage was severe, there were several factors which limited the disaster the earthquake might have caused.

First, the area subjected to the most damaging shaking was of small size, and it was immediately adjacent to a relatively undamaged urban area containing extensive fire, police, medical and other service facilities. These services were adequate to cope with the situation without becoming seriously overloaded.

A second fortunate factor was that most people were in their homes at the time of the earthquake, and the type of residential. construction common here is highly resistant to earthquake destruction. The typical light and strong wood frame house may be seriously cracked and damaged, but it seldom collapses completely with a major threat to life and limb. Only a very few, perhaps two or three, people were killed in their homes during this earthquake. If the shock had occurred just three hours later, the collapsed Psychiatric Day Care Center at the Olive View Hospital would have been occupied, the freeway overpasses would have collapsed on lanes of traffic and the falling debris from old buildings in San Eernando and Los Angeles would have pelted busy sidewalks. The resulting casualty toll would have been much more severe.

Another favourable factor was the lack of major landslides in densely populated areas. such slides were a major source of damage in the Alaskan earthquake of 1964 and in the 1970 peruvian earthquake, in which one major rock and ice avalanche buried two towns with an estimated 20,000 deaths. Fortunately, the possibility of such slides in the Los Angeles area seems small.

By far the most fortunate escape from disaster was the survival of the two Van Norman dams which were both severely damaged by the earthquake. The dams very nearly failed, and had the ground shaking lasted a little longer or had it been a little stronger, a catastrophic flood would have swept through a densely populated region before the inhabitants could have been evacuated. This is perhaps the most frightening aspect of this earthquake.

on the positive side, the earthquake provided a large amount of valuable data on ground and building motions that will notably increase engineering knowledge of earthquakes. Some 200 accelerographs recorded earthquake motions at various locations on the ground, in buildings, on dams, etc. These accelerographs, maintained by NOAA's National Ocean Survey and Caltech's Earthquake Engineering Research Laboratory, provided by far the greatest amount of strong-motion data so far recorded in any earthquake. Included in these results is the strongest ground shaking ever recorded. The record was obtained in the middle of the epicentral region on a steep rock ridge near the south abutment of Pacoima Dam. The concrete arch dam was not damaged.

The large collection of records obtained in the earthquake is extremely valuable from the point of view of research. For the first time there is enough data on the character of the ground motion and the response of structures to strong shaking to begin to answer some of the fundamental questions in earthquake engineering research. Such questions include how much the local geology affects ground motion; and what level of energy dissipation occurs in buildings under strong shaking.

\section{Lessons from the Earthquake}

The information gained from the San Fernando earthquake will aid greatly in efforts to reduce the disaster potential of future strong earthquakes. Many detailed studies are now underway to clarify particular features of the earthquake damage and to recommend ways to avoid damage in future shocks. Detailed recommendations and conclusions must await the results of careful study, but some general Iessons of the earthquake are already apparent.

(I) A striking consequence of the earthquake was the fact that four hospitals in the San Fernando area were damaged so severely that they were no longer operational just when they could be needed most. Certain critical structures should be designed so that they remain functional after experiencing the most severe ground shaking. Included are hospitals, schools, high-occupancy buildings, buildings housing police and fire departments and other agencies relied upon to cope with disasters. In addition to the structures, emergency communication systems of these agencies must receive special care so they will not be damaged. Basic utilities that must be depended upon for the life of the community must also receive an extra measure of protection.

ordinary building codes cannot be depended upon to preserve these functions, and special code provisions are necessary.

(2) This earthquake has provided the first really comprehensive practical test of U.S. earthquake codes. Modern structures designed according to the earthquake requirements of the building code performed well in the regions of moderately strong ground shaking. In the region of very strong ground motion, however, some modern buildings were severely damaged and the few that collapsed would have caused many additional deaths had they been occupied at the time. If the duration of strong ground shaking had been appreciably longer, as it would be in a great earthquake, some of the severely damaged structures would almost certainly have collapsed. It is clear that existing building codes do not always provide 
adequate safety against collapse, and such codes should be reviewed in detail and updated to include the latest practical developments in earthquake engineering.

(3) Many old, weak buildings in the regions of strong and moderately strong shaking suffered severe damage, and the major loss of life occurred in one old building designed before the adoption of modern building codes. There are many thousands of such old buildings in California that will collapse if subjected to strong ground shaking. Programs should be undertaken to render such buildings safe, or to raze them, over a reasonable period of time. A successful effort of this type has been underway for some time in the City of Long Beach, and in the City of Los Angeles especially hazardous parapet walls on several thousand buildings have been removed or strengthened. The San Fernando earthquake dramatically demonstrated the value of such procedures. A much more extensive program to eliminate the major hazards of old buildings is needed.

(4) The near catastrophic failure of the lower Van Norman dam endangered the lives of tens of thousands of people. Such risks are clearly unacceptable. A program for bringing older dams up to modern safety standards is imperative because many existing dams in all parts of the country have not been designed to resist earthquake forces. Such structures should be thoroughly examined and measures taken to reduce such hazards to an acceptable level. The successful performance of a new earth-fill dam at the Van Norman site shows that modern earthfill construction can withstand the earthquake forces that damaged the older dams.

(5) A number of freeway overpass bridges collapsed causing two deaths and resulting in major disruptions of traffic. In a great earthquake, such interruptions of transportation could greatly magnify the disastrous effects of the earthquake. Freeway bridges, and important highway bridges, should be designed for adequate safety against collapse.

Present standard code requirements for earthquake design of highway bridges are inadequate and should be revised in conformity with the current state of knowledge in earthquake engineering.

(6) It is noteworthy that school buildings in the region of strong shaking designed and constructed under the Field Act of the California State Legislature did not suffer structural damage that would have been dangerous to the occupants had the schools been in session. This demonstrates that one- and two-storey school buildings can indeed be made safe by practicable code requirements even when subjected to very strong shaking combined with appreciable ground deformations beneath the structures. on the other hand, older school buildings that did not meet the requirements of the Field Act suffered potentially hazardous damage in regions of only moderately strong ground shaking. The lessor. is clear that such hazardous school buildings must be eliminated or strengthened.

(7) None of the tall buildings in Los Angeles was seriously damaged by the earthquake, but it should be emphasized that this earthquake was too far away from downtown Los Angeles to be a good test of the strength of those structures. Tall buildings, like other buildings, can be made to resist the strongest shaking without collapse, but this does not occur automatically. Uniess the special carc devoted to the design of recent tall buildings is continued in the design of others, tall buildings, too, can be a hazard in the event of strong shaking.

(8) The extensive damage to electrical transmission facilities shows that the earthquakeresistant design of these facilities must be markedly improved. It has been estimated that it will be at least a year before repairs are completed at the Sylmar Converter station, which suffered approximately $\$ 30$ million damage.

(9) The approximate damage cost of $\$ 500$ million and the effects on vital services from a moderate earthquake occurring on the fringe of the Los Angeles metropolitan area point out the large disaster potential of major earthquakes. If the shock had occurred near the center of the city, or if a great earthquake should occur on the San Andreas fault, it would seem that the damage could approach three or four billion dollars and essential services would be severely crippled. The rapid recovery from the San Fernando earthquake showed that the disaster was not too large for the recuperative powers of the metropolitan area to overcome; the utilities, medical and protective systems handled the increased burden very well, and relative normalcy has been approached in a matter of days or weeks. It is not expected, however, that such systems could overcome the consequences of a great earthquake without major assistance from outside the metropolitan area.

(10) The San Fernando earthquake again demonstrated that the most practical approach to the problem of safety in earthquakes is earthresistant design. Structures can be designed to withstand safely the most severe earthquakes, but this cannot be done without an increase in cost. For many buildings, and other structures, this increase in cost is a modest one; for others it may represent a significant increase in overall investment.

Once essential function and safety of life and limb has been assured, the problem of earthquake-resistant design becomes an economic problem; the initial cost must be balanced against the possible cost of repair to earthquake damage over the expected lifetime of a structure.

The San Fernando earthquake, though a disaster to many, has provided a unique opportunity to learn about the effects of strong earthquake motion. The results of the many engineering studies now underway, and the actions and regulations prompted by this earthquake should reduce significantly the hazard from earthquakes of the future. 


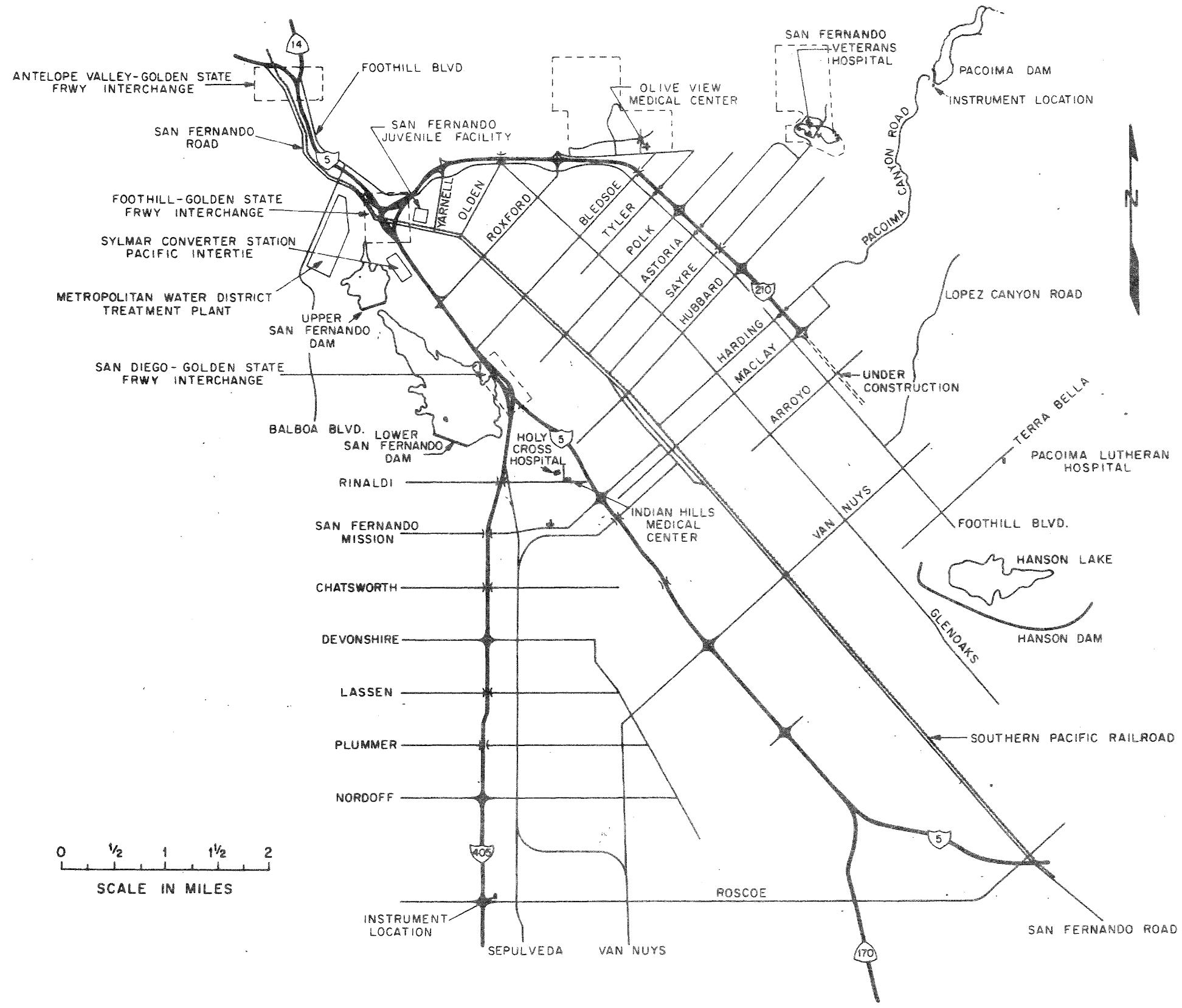

NORTHERN SAN FERNANDO VALLEY

Fig 1: Location of major structures. The epicenter was 5 miles due north of Pacoima Dam, but the dam site was the approximate centre of energy release of the magnitude 6.6 earthquake. 


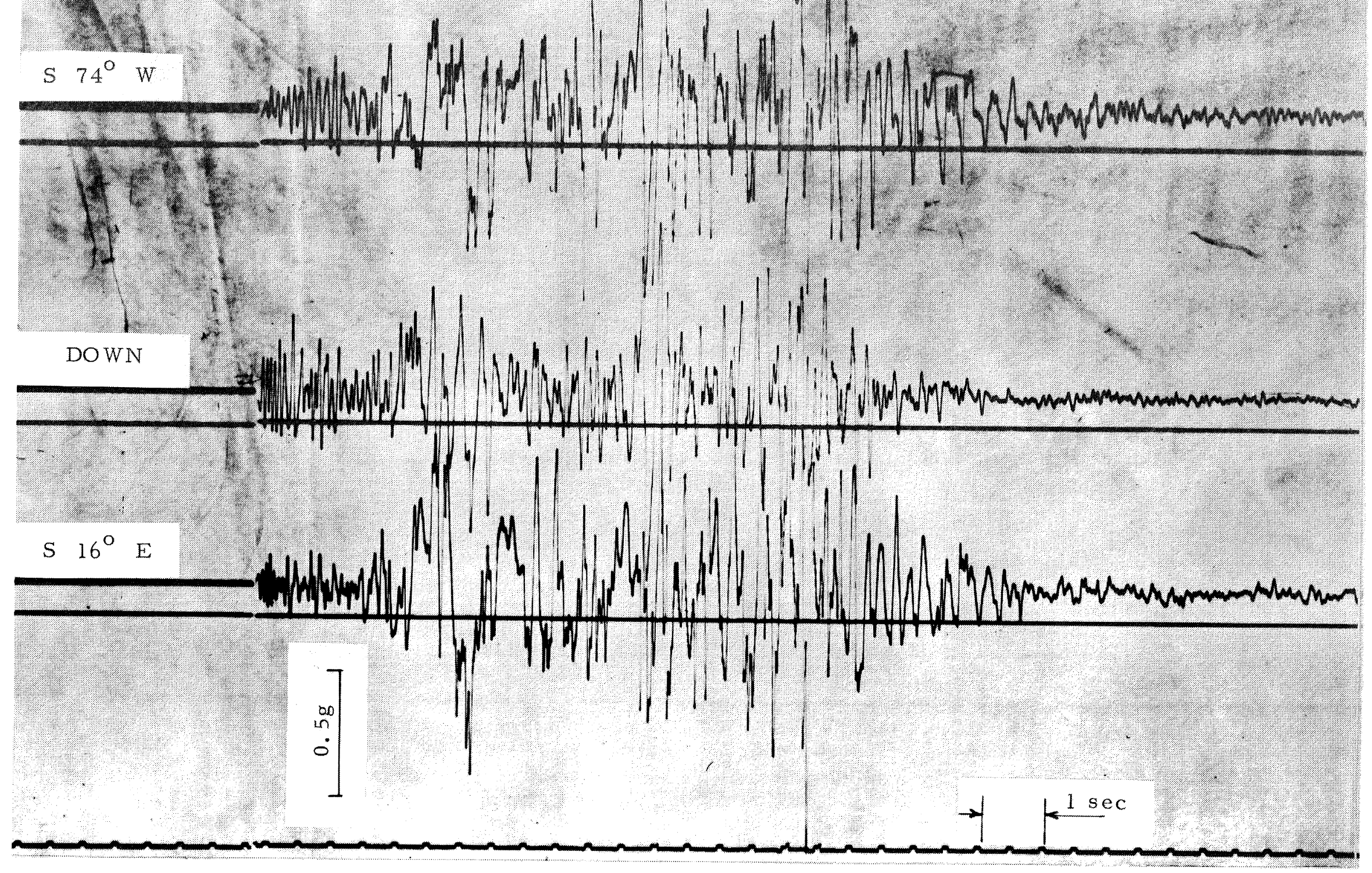

Fig 1A: Strong-motion accelerograph record of the main shock of the San Fernando earthquake. Recorded on a rock ridge at the Pacoima Dam site five miles from the epicenter. 


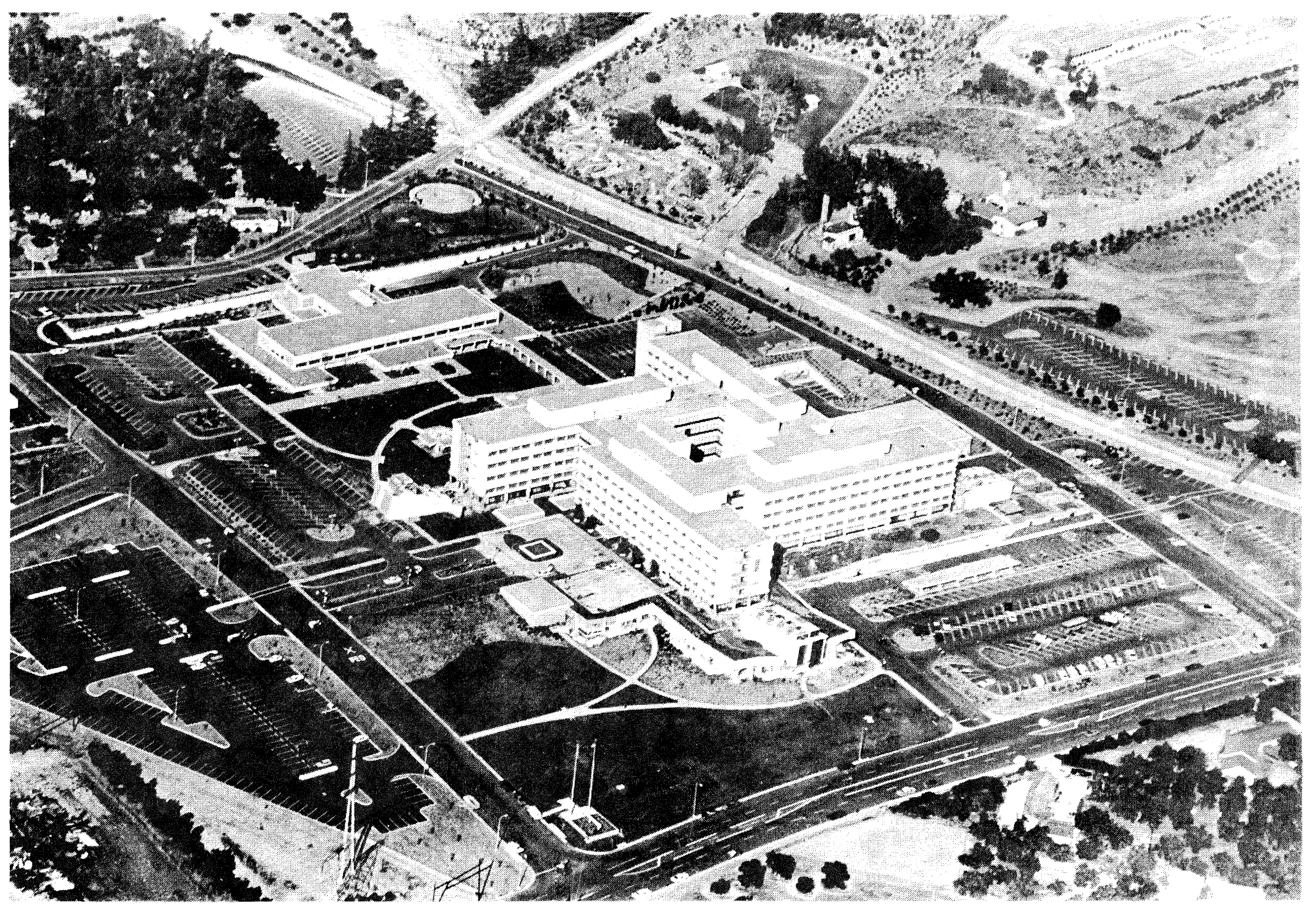

Fig 2: The new complex of buildings at the Olive View Hospital. These reinforced concrete buildings were put into service in October, 1970. All the buildings experienced structural failures. At the upper left the two-story psychiatric ward suffered a collapse of the lower story. In the center the four main five-story wings were severely damaged, and three of the utility towers at the ends of the wings toppled. 
Fig 3: The lateral loadresisting elements of one of the five-story wings at olive View Hospital are shown in this view. In tha long direction the building acts essentlally as a frame. The first-story is considerably more flexible than the upper stories where the external beams and wall panels reduce the effective column heights. In the short direction the first-story acts as a frame but in the upper floors the end frames are filled with reinforced concrete walls. The collapsed structure in the foreground is an ambutance parking pergola.

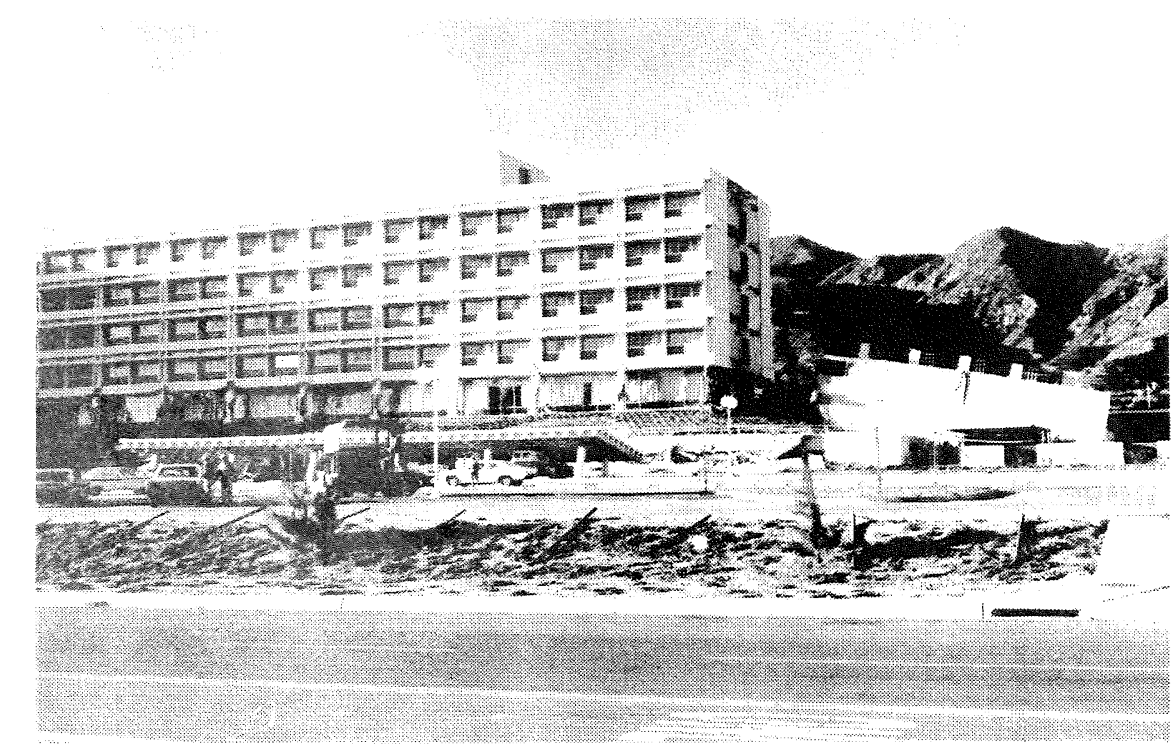

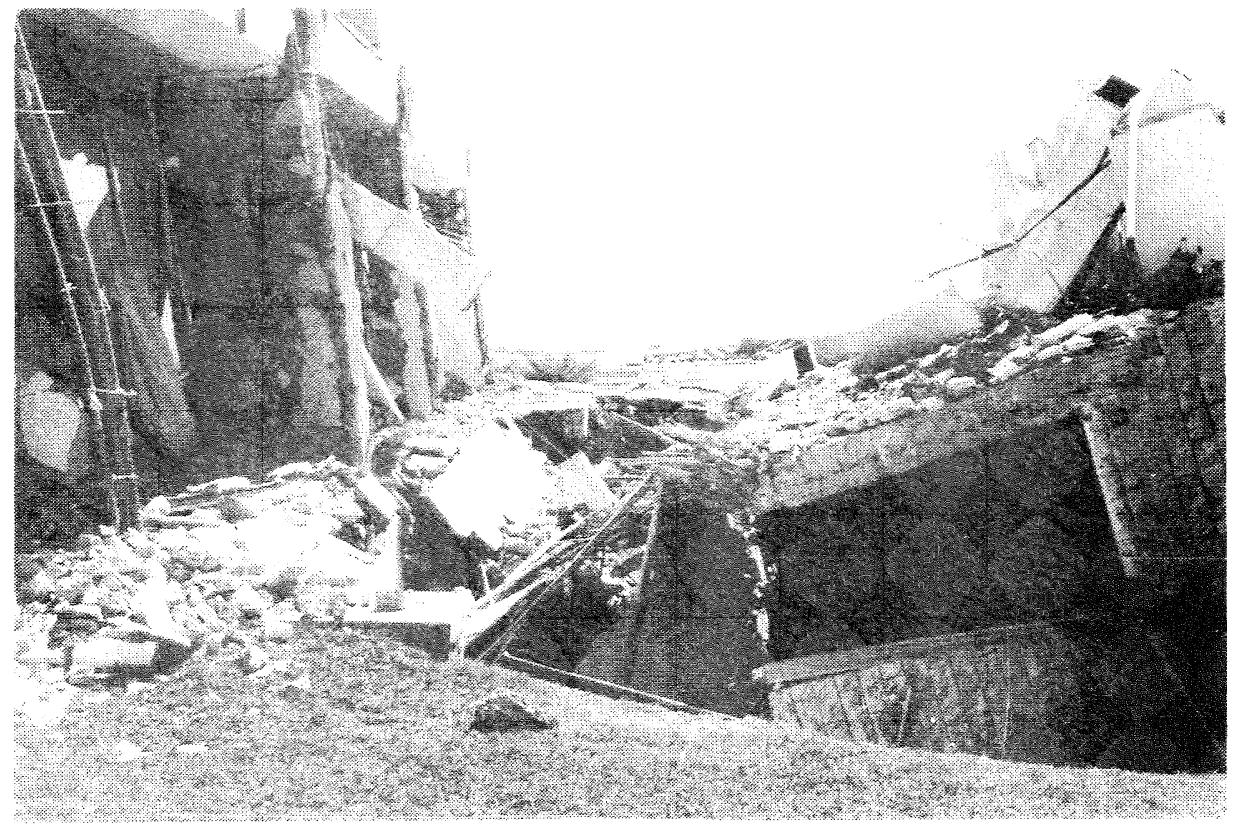

Fig 4: The ground level failure in one of the utility towers. These towers contained staircases and television rooms. Although structurally separate from the main wings, they were in contact and were apparently subjected to severe hammering before the ground level reinforcement splice failed. The towers were supported by a beamcolumn system in the basement story and the walls did not continue below ground level. Olive View Hospital. 

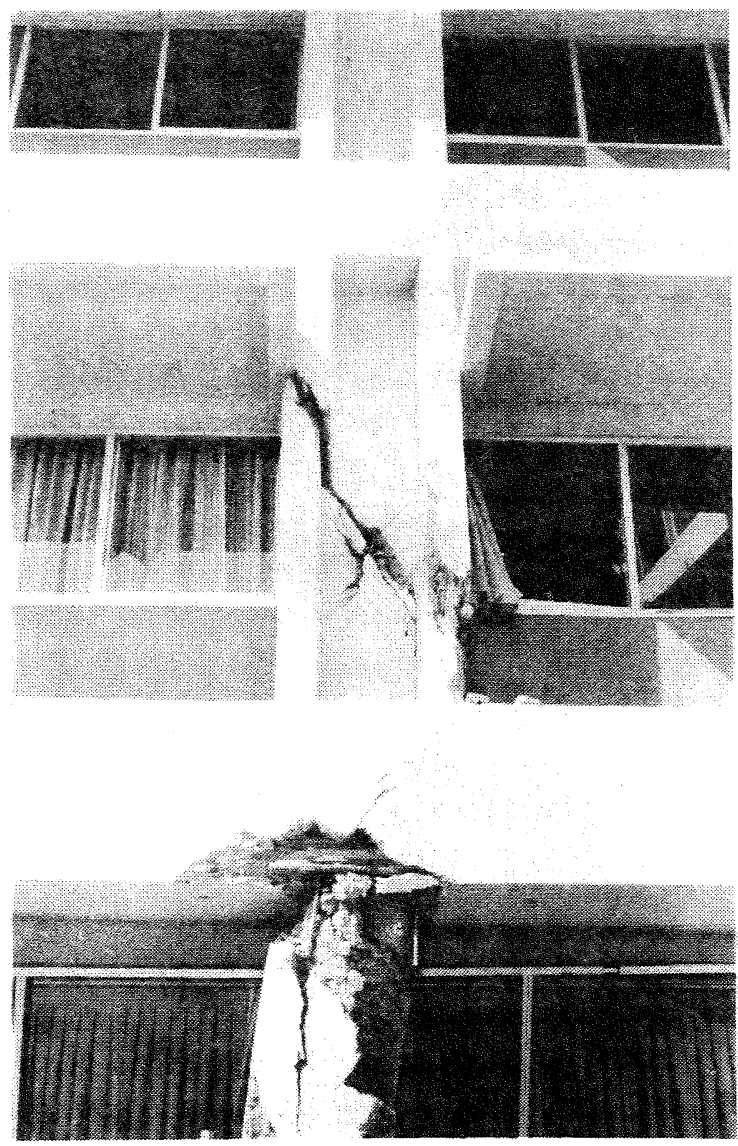

Fig 5: Failures of the first-and second-story columns in one of the five-story wings. The spirally wound first-story columns failed in bending and many of the tied 1 -section columns in the second-story failed in shear. Olive View Hospital.
Fig 6: First-story columns in one of the five-story wings. The corner columns are L-shaped tied columns. The remaining exterior columns are essentially spiral columns. Four No. 14 dowels extend out of the basement columns and form tied corner bars outside the spirals. Olive View Hospital.

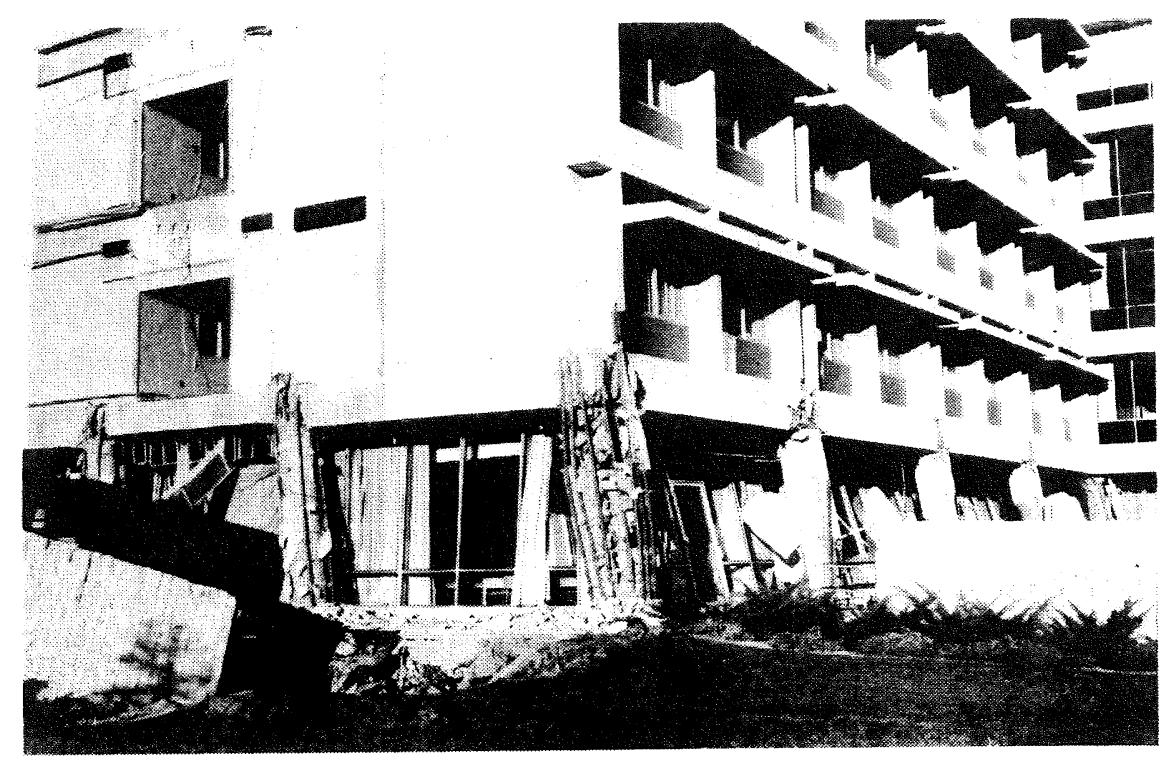


Fig 7: A closer view of the tied L column shown in Fig 7. It is interesting to compare this fallure with the less extensively damaged spirally-wound column shown in Fig 8 . Olive View Hospital.
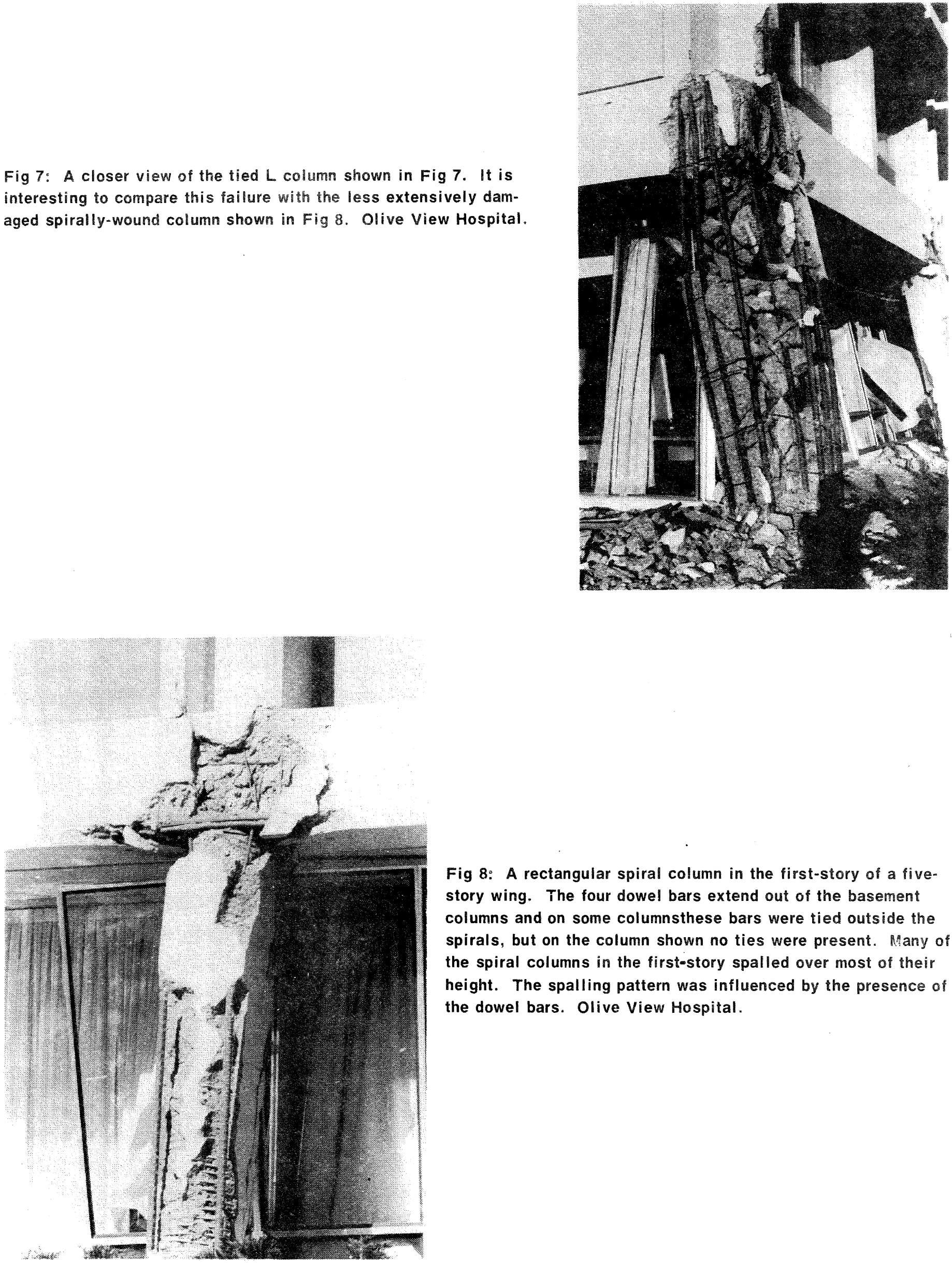

Fig 8: A rectangular spiral column in the first-story of a fivestory wing. The four dowel bars extend out of the basement columns and on some columnsthese bars were tied outside the spirals, but on the column shown no ties were present. Many of the spiral columns in the first-story spalled over most of their height. The spalling pattern was influenced by the presence of the dowel bars. Olive View Hospital. 


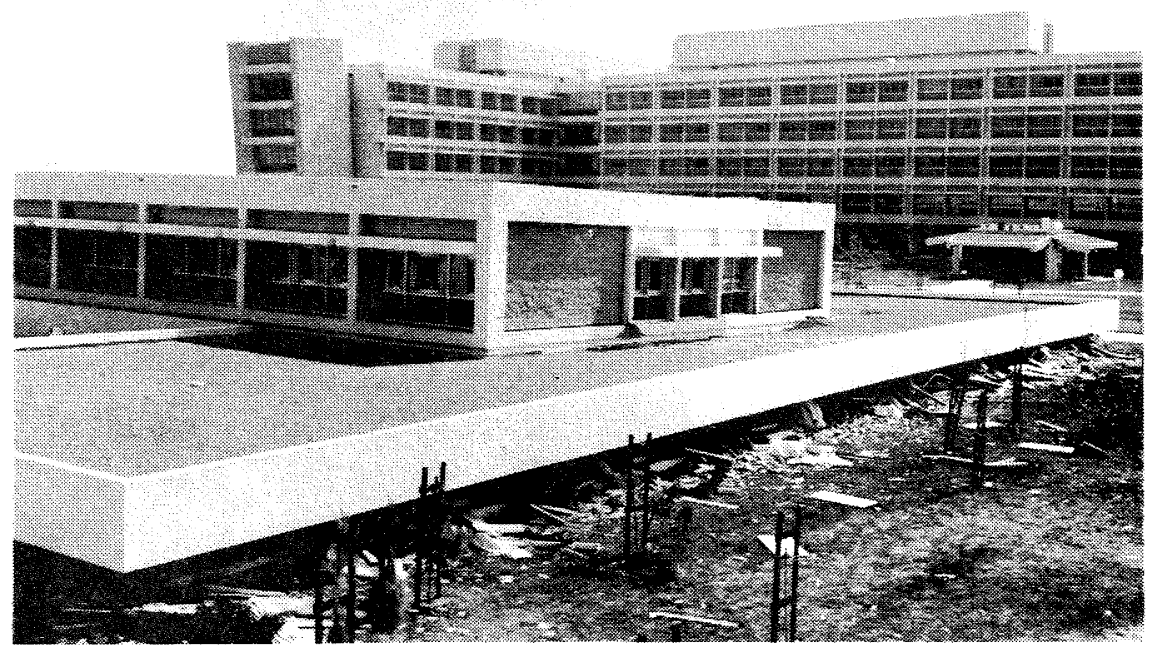

Fig 9: The Psychiatric Ward at olive View Hospital. The reinforced concrete columns in the first-story disintegrated lowering the second-story floor slab almost to ground level. The pile of rubble around the perimeter is mainly concrete from the columns

Fig 10: Some of the first-story columns in the Psychiatric Ward at Olive View Hospital. Lightweight concrete was used in the rectangular tied columns. 
Fig 11: The seven-story Holy Cross Hospital. This modern reinforced concrete building received extensive structural damage and was evacuated soon after the main shock. In the short direction the main lateral loadresisting elements are the external shear walls and the interior elevator tower. The elevator tower provides the primary resistance to lateral loads in the long direction. Note the failure in the shear wall at the right (eastern) end of the building.
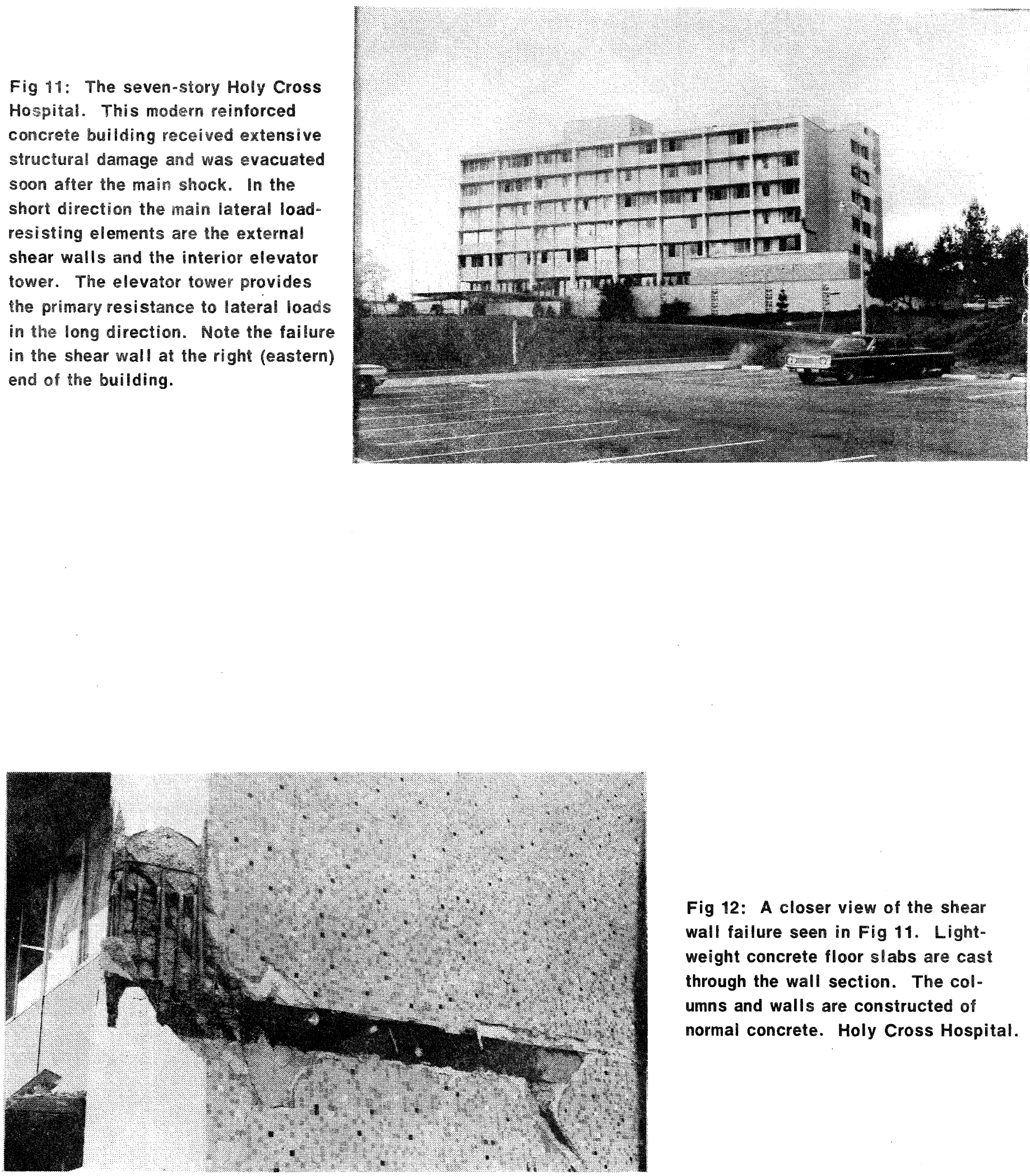

Fig 12: A closer view of the shear wall failure seen in Fig 11. Lightweight concrete floor slabs are cast through the wall section. The columns and walls are constructed of normal concrete. Holy Cross Hospital. 


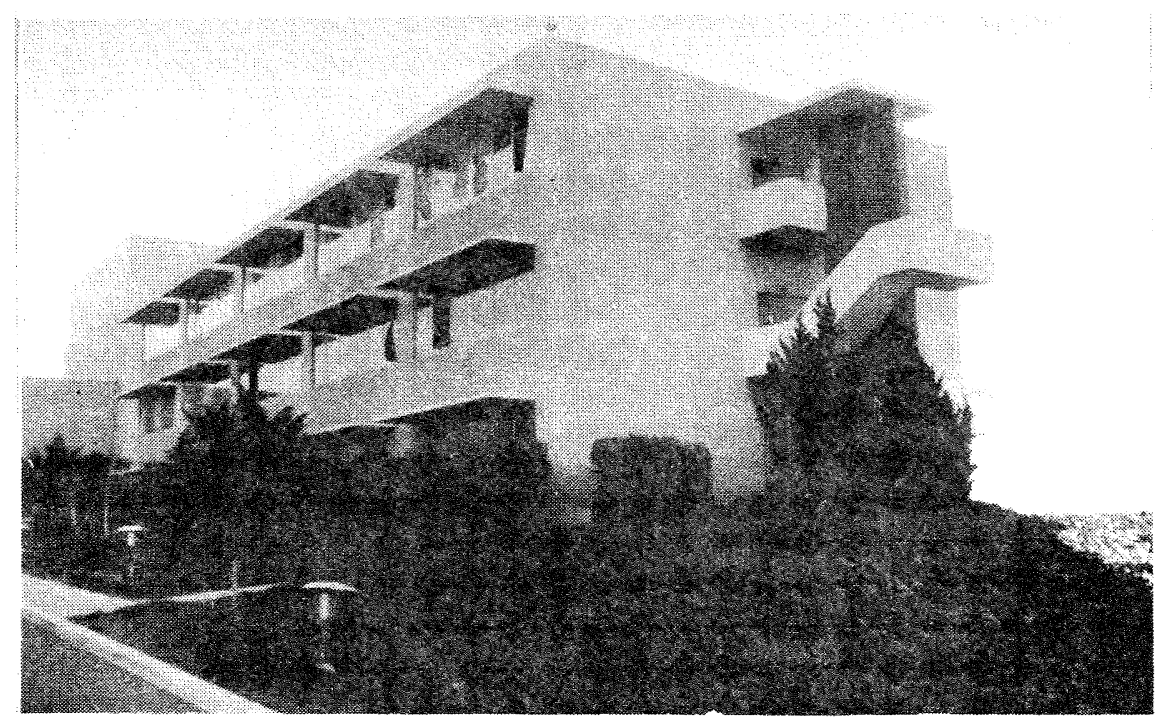

Fig 13: The three-story wing at the Pacoima Lutheran Hospital. This building, a reinforced concrete struct ure, approximately ten years old, received extensive structural and nonstructural damage. In the short direction reinforced concrete shear walls resist the horizontal loads and in the long direction lateral loads are carried by the elevator and stair tower. The location of the tower at one end of the building produces a torsionally out of balance structure.

Fig 14: Structural damage in a shear wall at the elevator tower end of the building. The interior plaster was badly cracked by the vibrations of the building. The building has a basement level and the backfilling placed on one side of the building settled approximately $9 \mathrm{in}$. Pacoima Lutheran Hospital. 
Fig 15: spalling and cracking of a staircase in the three-story wing at Pacoima Lutheran Hospital.

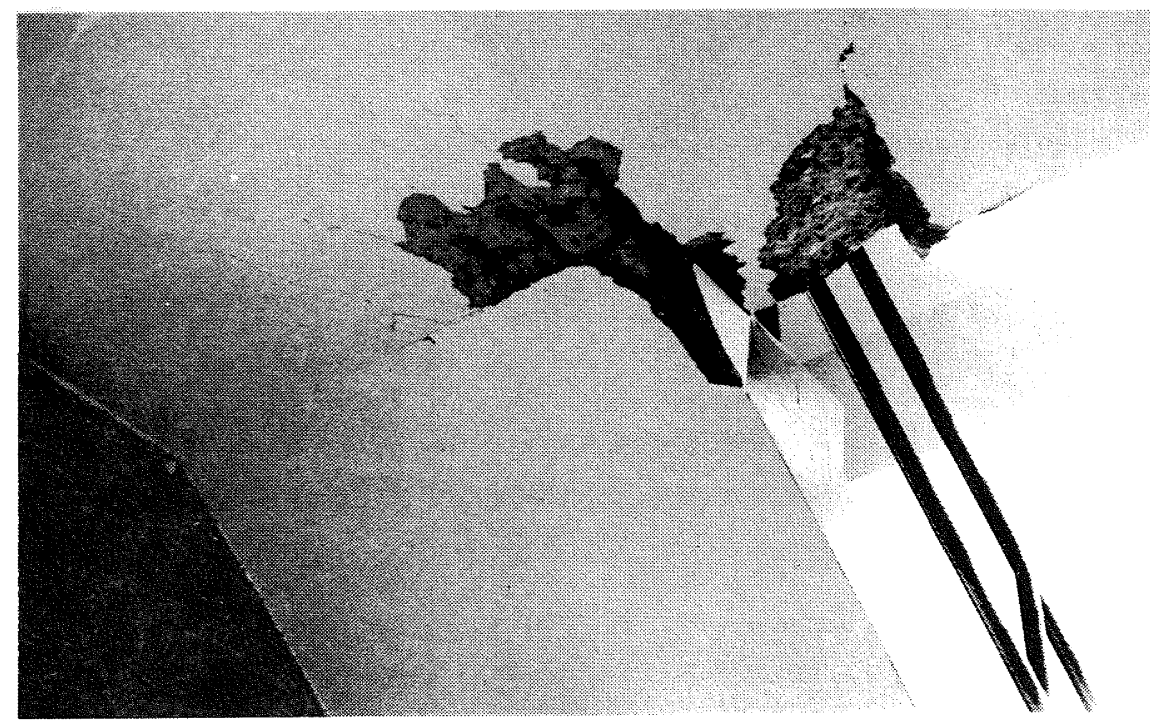

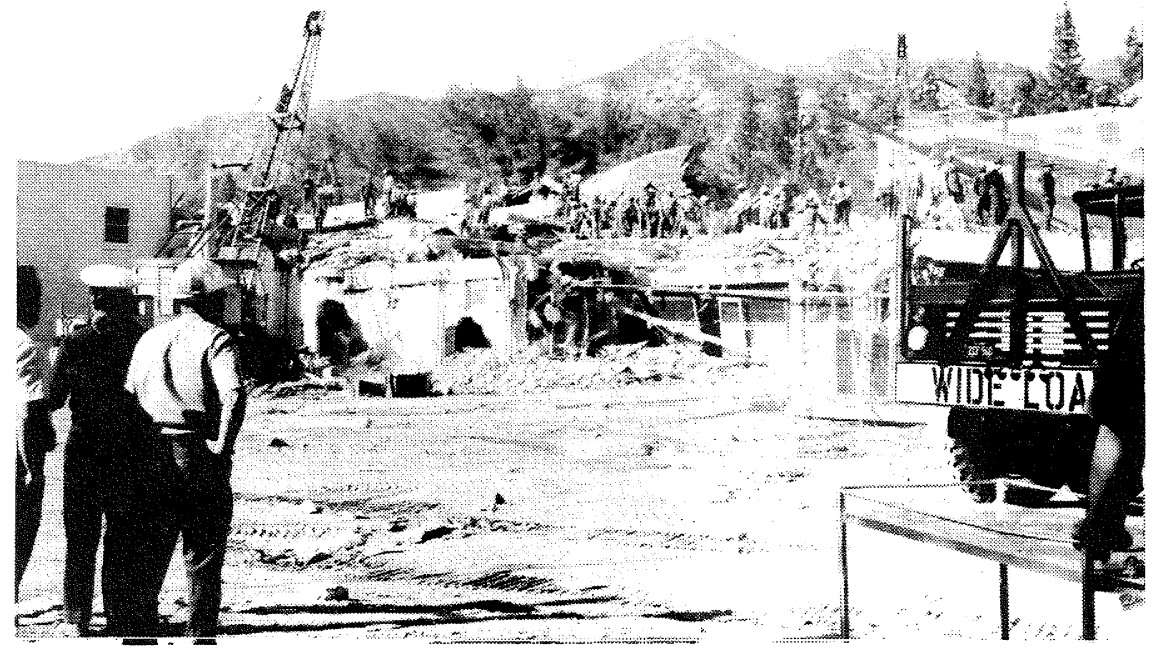

Fig 16: Careful removal of the rubble in search for survivors at the Veterans Administration Hospital where 44 persons were killed. A number of threestory buildings built in 1926 collapsed. Newer buildings at the hospital, built in 1937 and 1947, received no signif icant structural damage. The site is approximately 1.5 miles from the Pacoima Dam where the $1.0 \mathrm{~g}$ peak acceleration was recorded. 


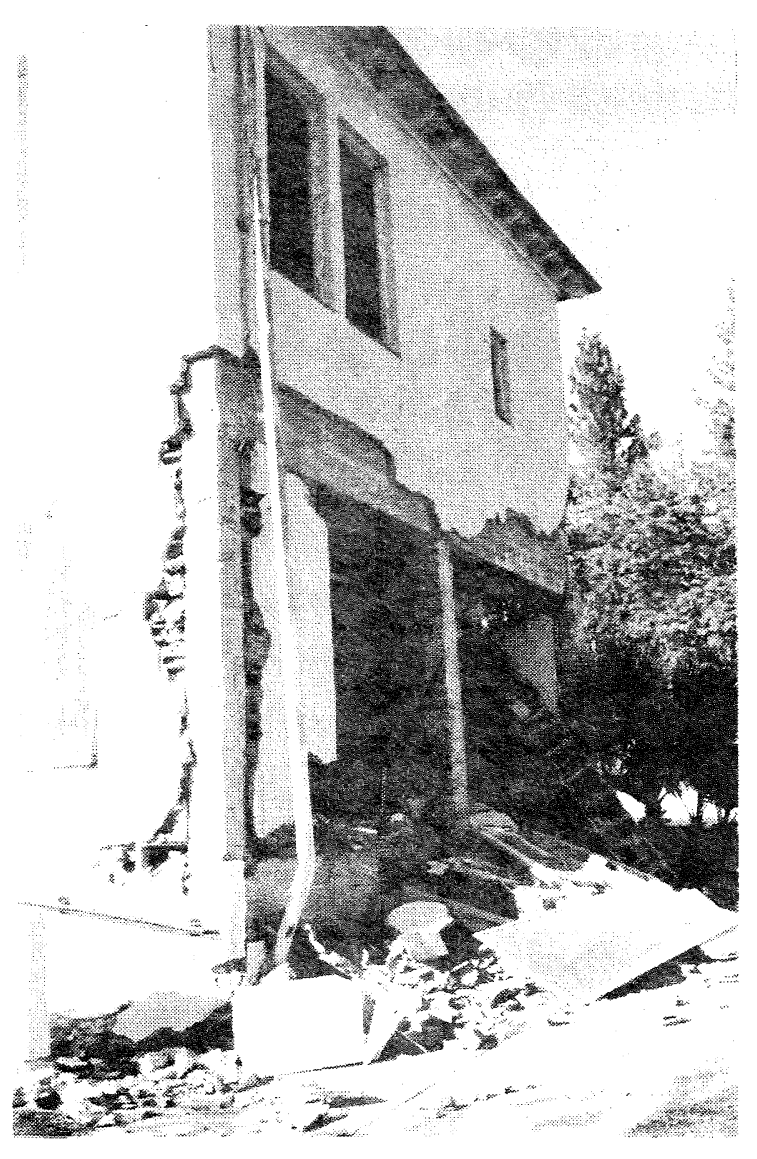

Fig 17: A building at the Veterans Administration Hospital Site. This view shows the type of construction of the buildings that collapsed. Filter-tile walls are constructed between the reinforced concrete frames.

Fig 18: The Indian Hills Medical Center is a six-story office building on a site adjacent to the Holy Cross Hospital. Lateral loads are resisted by eight external reiniorced concrete shear walls arranged to give approximately equal resistance about both major axes of the building. An internal reinforced concrete frame supports the lightweight concrete floor slabs.

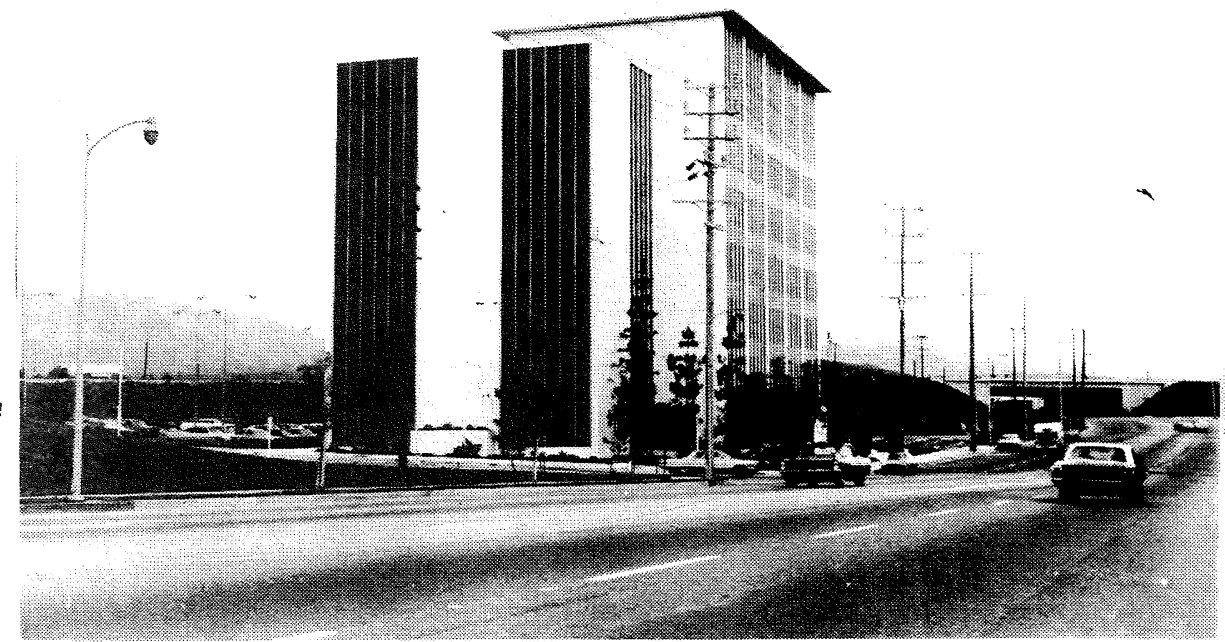


Fig 19: Typical shear wall damage The $45^{\circ}$ cracking extended the full height of the walls. Fallure along the horizontal construction joints above the lloor slabs was very pro. nounced, and permanent displace. ments on the joints of more than yin were observed on most walls. The lightweight concrete floor slabs were cast across the wall sections and this method of construction had undoubtedly contributed to the extent of the horizontal shear failures. The walls are 8 in thick with vert ical edge thickening of approximate dimensions of 18 in $\times 20$ in. Quite visible cracking in the upper story wall sections suggested that a con-

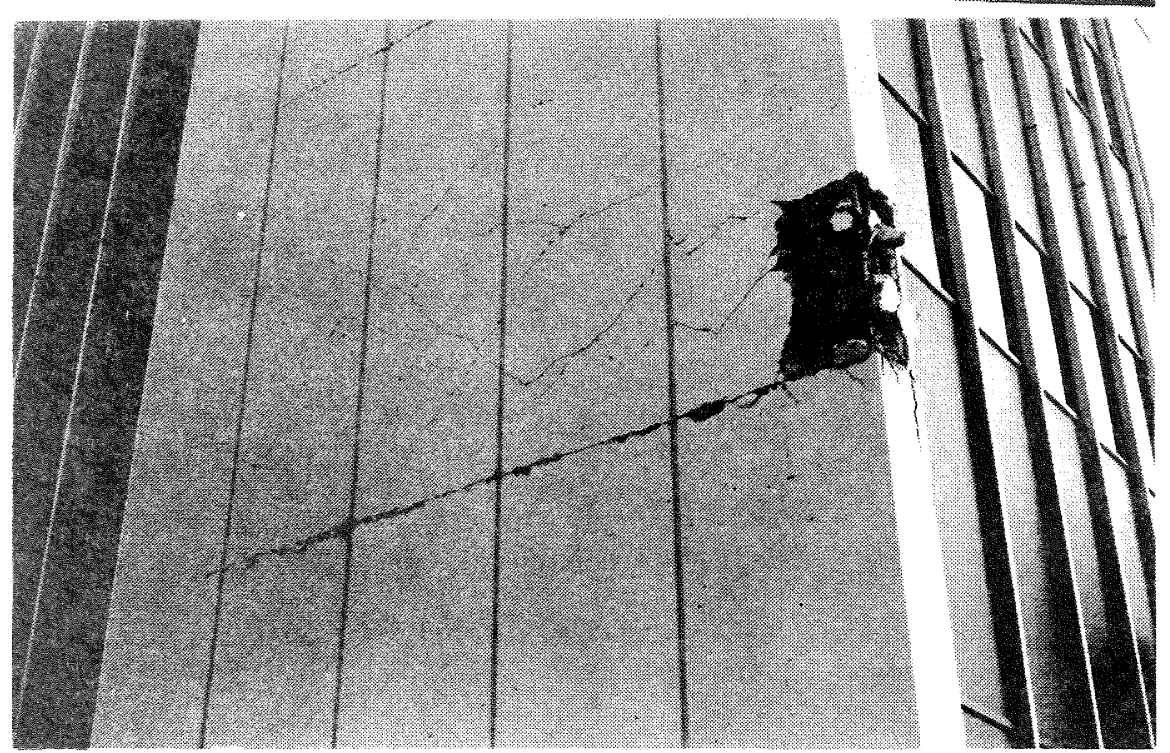
crete of lower strength was used at the higher levels. Indian Medical Center.

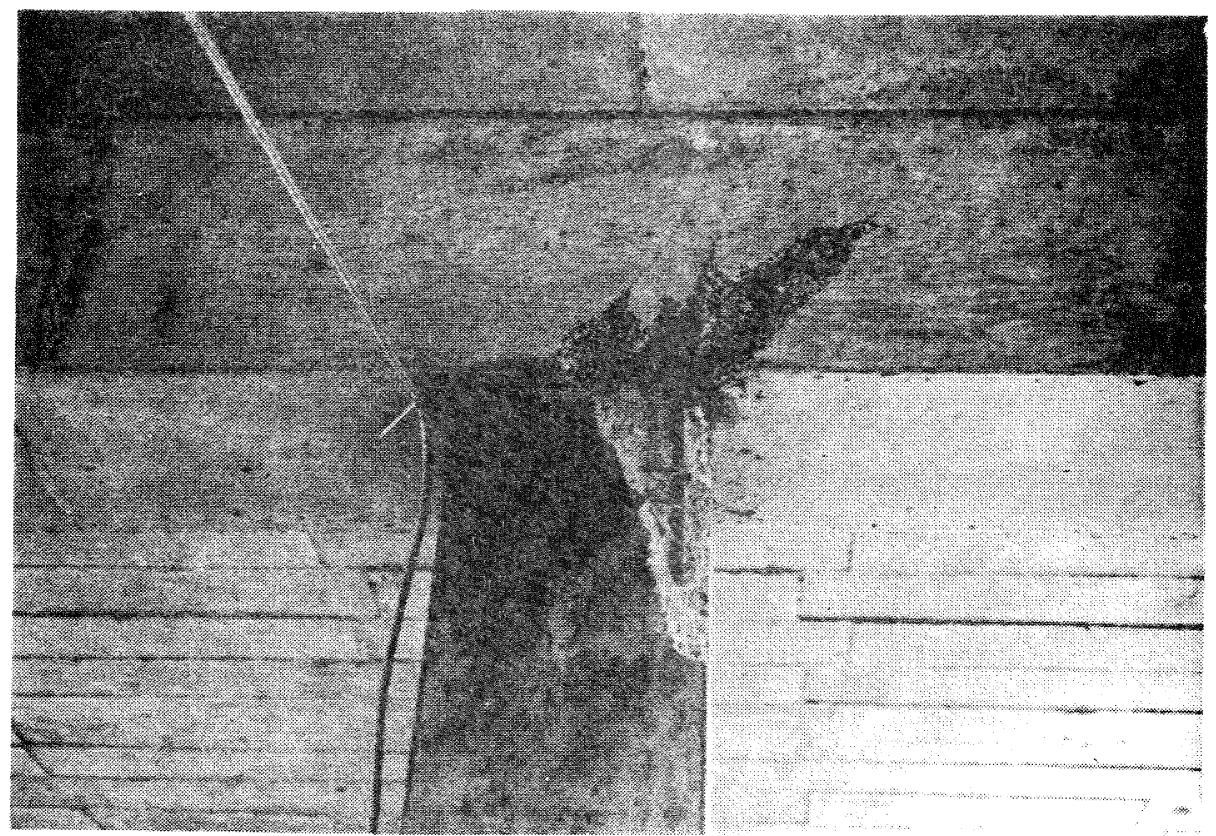

Fig 20: The internal frame received a moderate amount of cracking and spall. ing. This view shows a beam-column junction in the fourth-story. The frame damage appeared to be more severe in the upper floors, but full inspection of the building was not possible. The beam is lightweight concrete and 18 in $\times 18$ in column is constructed of regular concrete Indian Hills Medical Center. 


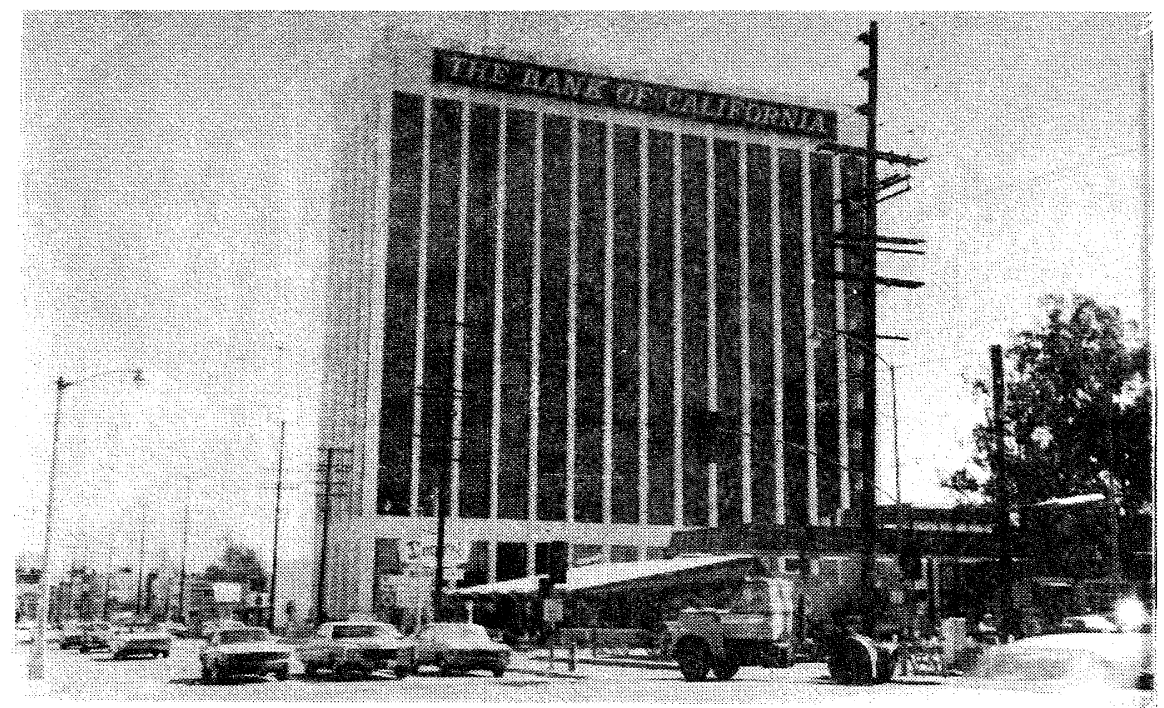

Fig 21: The twelve-story Bank of California building was located 16 miles south of the epicenter of the main shock, and is of particular interest because it houses three strong-motion accelerometers. A reinforced concrete frame is used to resist lateral loads. A horizontal accel. eration peak of $0.2 \mathrm{~g}$ was reached in the basement, and at the roof level a maximum horizontal peak of $0.28 \mathrm{~g}$ was recorded.

Fig 22: The reinforced concrete frame received a moderate amount of damage and this view shows an exterior section of the building after the cracking had been filled with epoxy. Bank of California. 
Fig 23: Permanent ground displacments and structural damage at the San Fernando Juvenile Facility. This larger new facility has a plan shape in the form of a pentagon surrounding an interior courtyard. Many of the buildings received extensive damage from both permanent/ground movements as well as shaking of the ground. In this view, evidence of the permanent ground displacements, which probably caused the collapse of the roof in the foreground, are visible on the parking lot. The reinforced concrete columns supporting the timber roof failed.

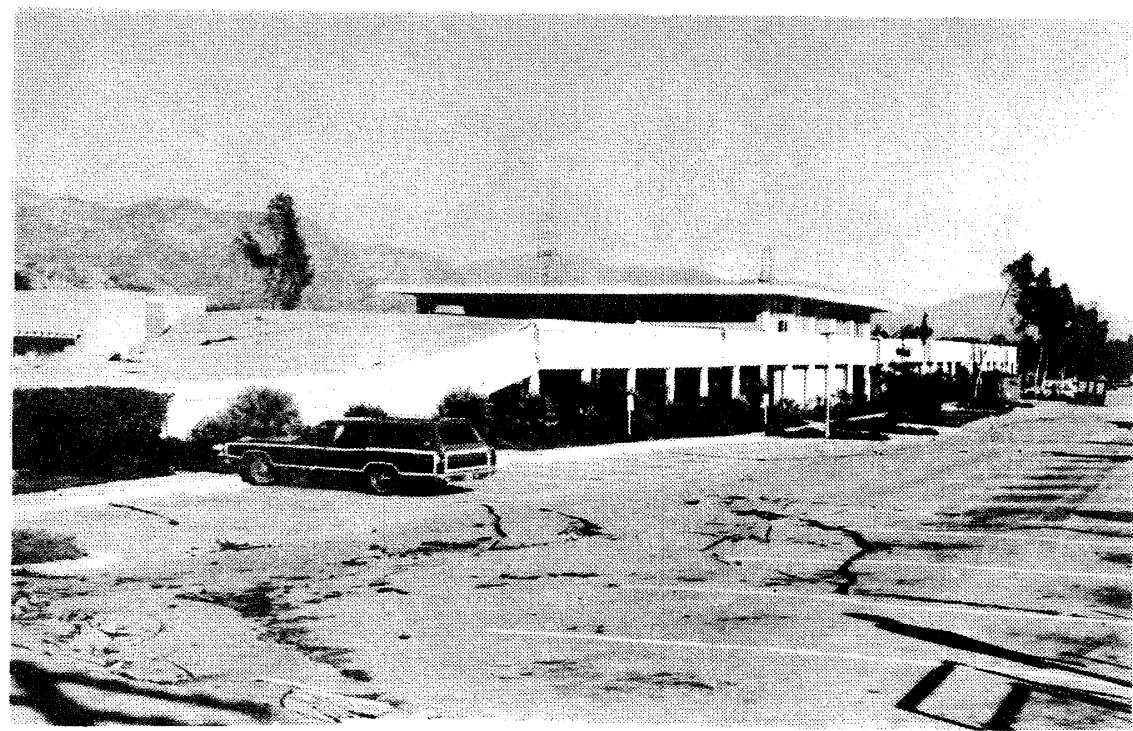

Fig 24: The combined effects of permanent ground shortening and structural hammering resulted in extensive damage to a number of block walls at the San Fernando Juvenile Facility. 


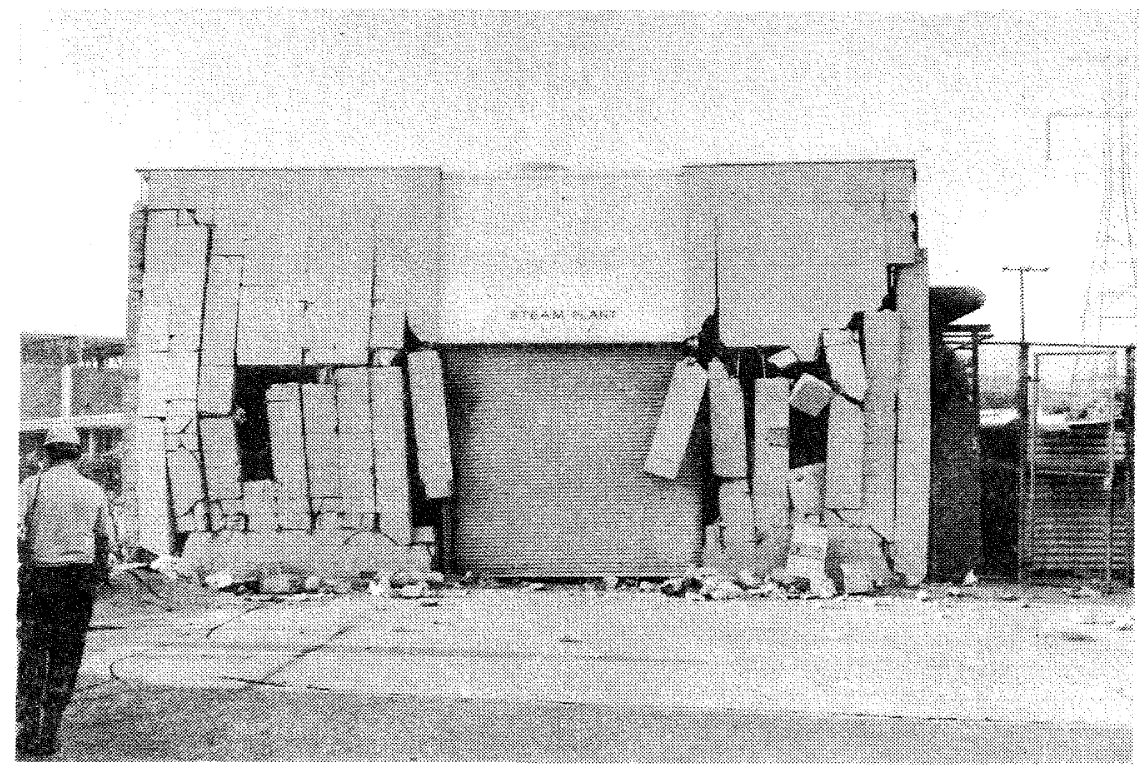

Fig 25: Failure of a concrete-block wall. Vertical reinforcing bars were grouted into the hollow blocks. The failure pattern indicates that insufficient horizontal tieing between the blocks was provided. San Fernando Juvenile Facility.

Fig 26: This roof and wall collapse occured at the Vector Electronics building. The roofs collapsed on approximately 20 similar single-story industrial buildings in the San Fernando area. Many of the single-story industrial buildings in this locality are of tilt-up reinforced concrete wall construction with laminated timber beams supporting a plywood roof cladding. The roof beams commonly span about $80 \mathrm{ft}$, and longer roof structures are achieved by splicing of the beams and addition of 6 in., diameter steel columns. The wall slabs are commonly $20 \mathrm{ft} \times 20 \mathrm{ft} \times 6$ in and are connected together by a castin-place reinforced concrete column. The lack of sufficient rigidity in the long

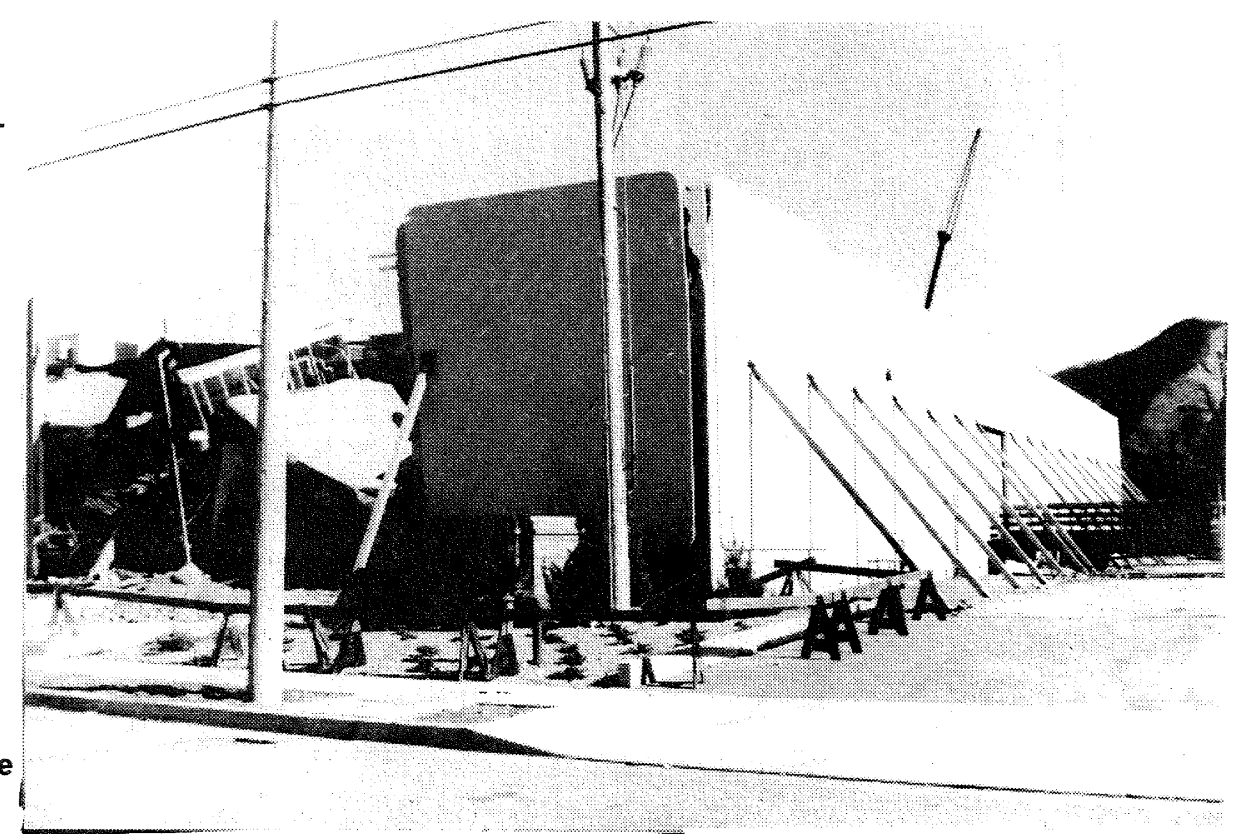
span roof structures and interior supports resulted in appreciable horizontal loading being transmitted to the exterior tilt-up walls in a direction normal to their plane. The roof-to-wall connection and wall-to-ground slab connections had no appreciable moment resistance and after repeated severe vibrations, the roof connection failed followed by collapse of the roof and outward displacement of the walls. 
Fig 27: Several iwo-story apartment buildings received extensive damage. The wooden tramed, stuccomclad building shown had large openings in the lower story
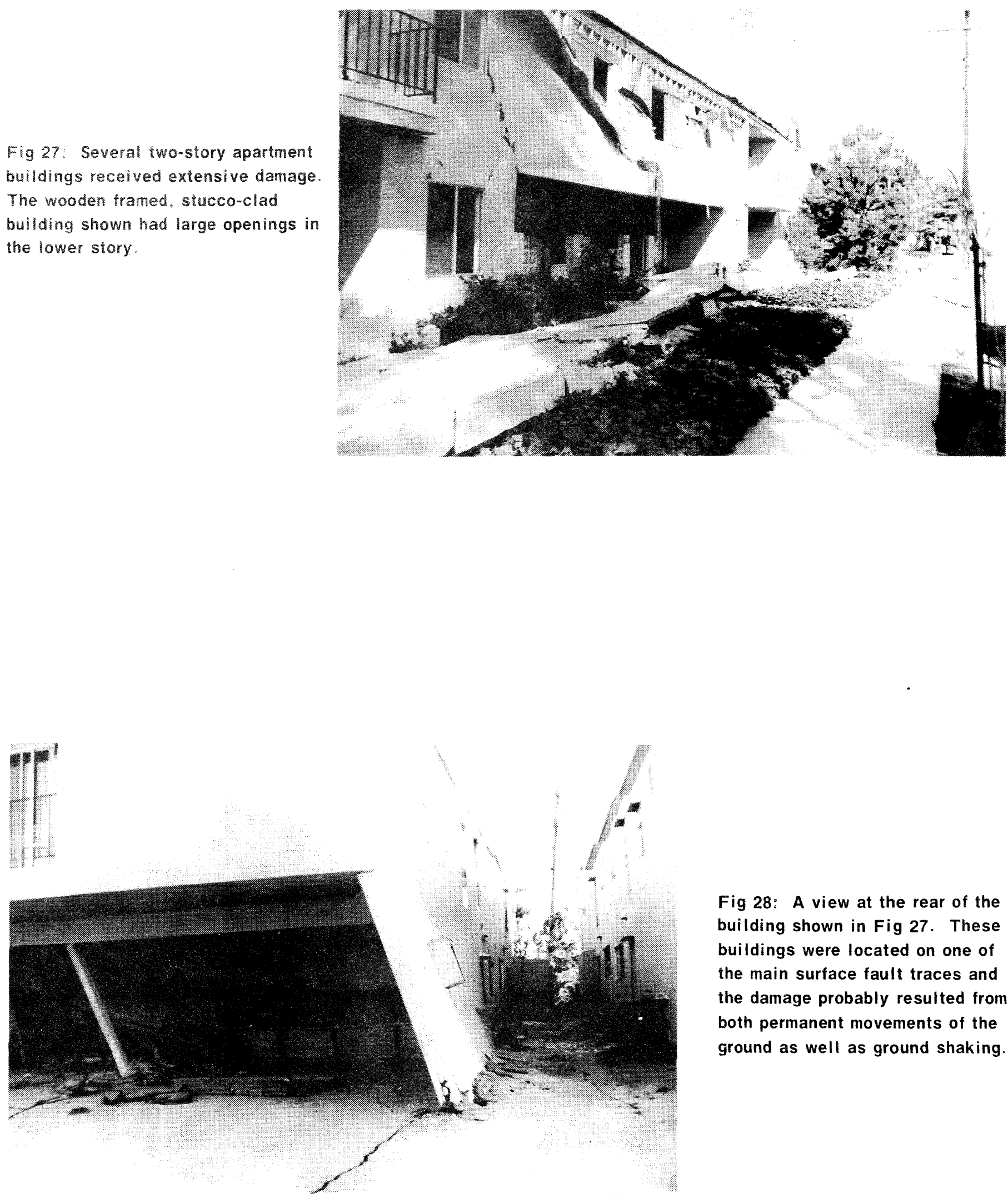

Fig 28: A view at the rear of the building shown in Fig 27. These buildings were located on one of the main surface fault traces and the damage probably resulted from both permanent movements of the ground as well as ground shaking 


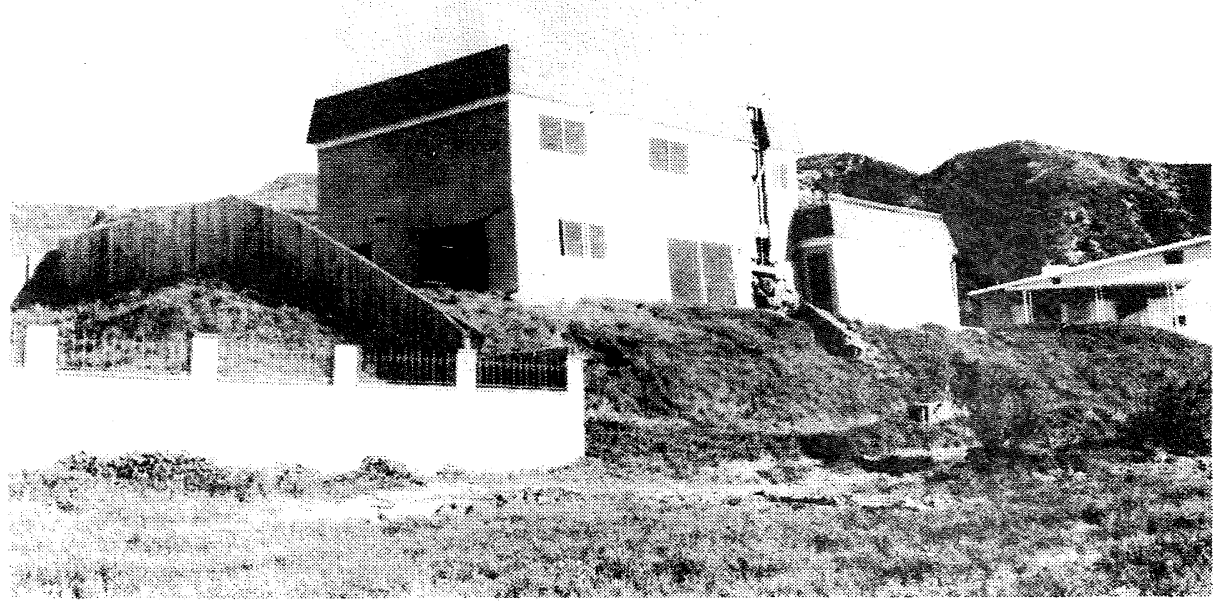

Fig 29: A two-story, timber framed, stucco-clad house with large openings in the lower story. In general, with the exception of houses located on fault traces, the single-story timber framed dwellings survived without extensive structural damage. Many of the most extensively damaged houses and apartments were either two stories or of split-level construction.

Fig 30: The collapsed chimney on the house shown in fig 29. In this particular case the larger deformations of the failing house structure would have been sufficient to force the chimney to crack and collapse. However, chimney failures were widespread and quite common on houses that received no other significant damage. Many of the new houses in the San Fernando Valley had chimneys of reinforced brick construction.

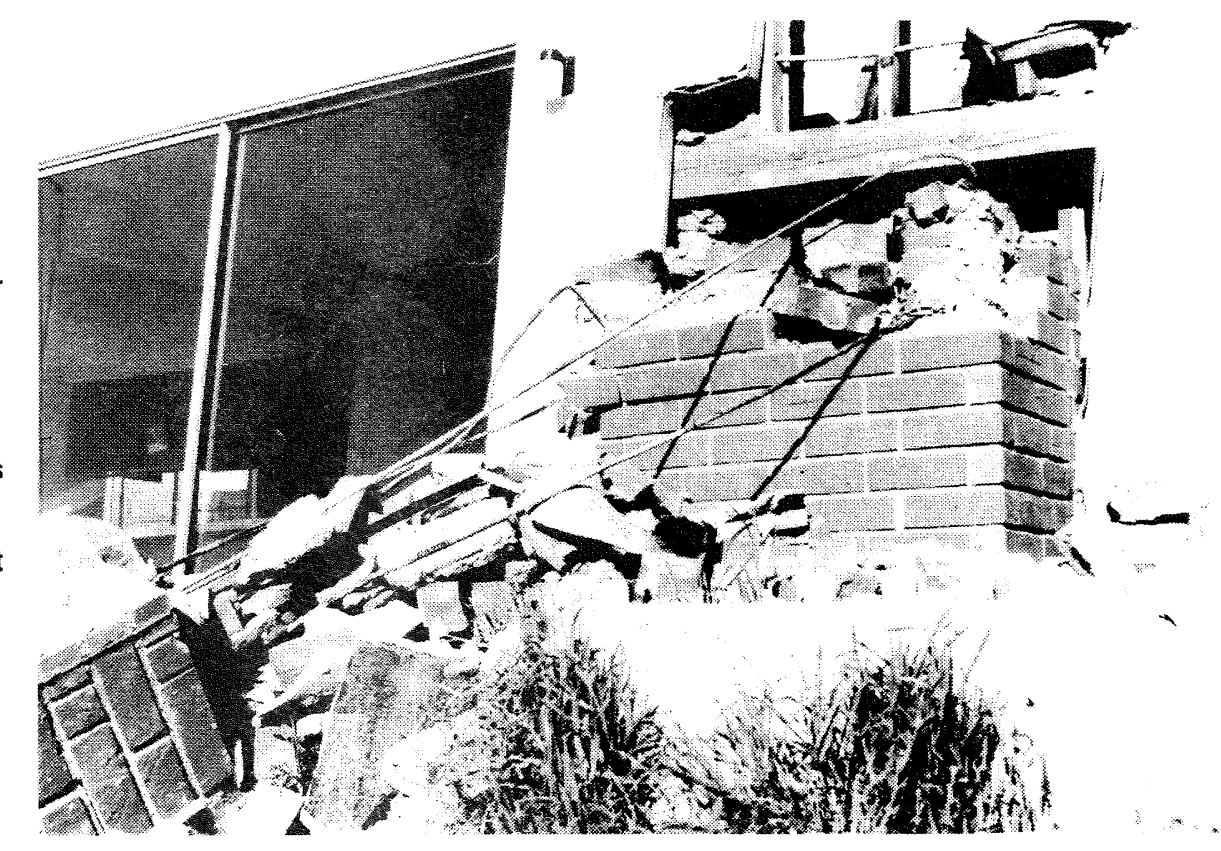


Fig 31: Severely damaged timberframed, split-level houses near the Olive View Hospital. The major weaknesses appeared to be: the structural separation of the main walls from the concrete foundation by the use of a short height of timber framing, weak connections between the individual levels, and large openings.

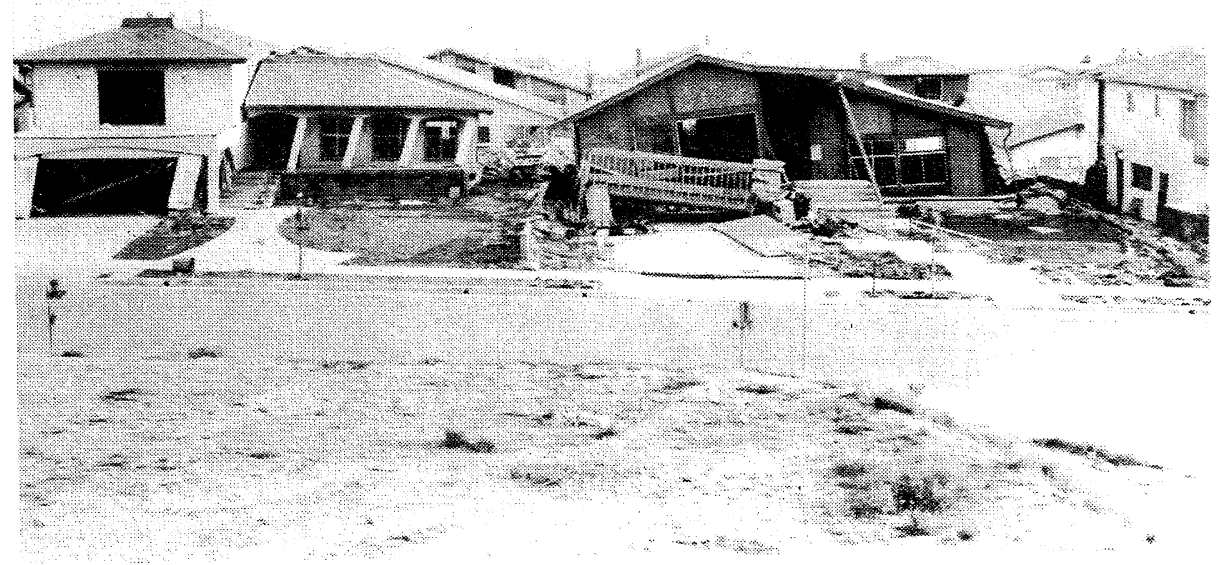

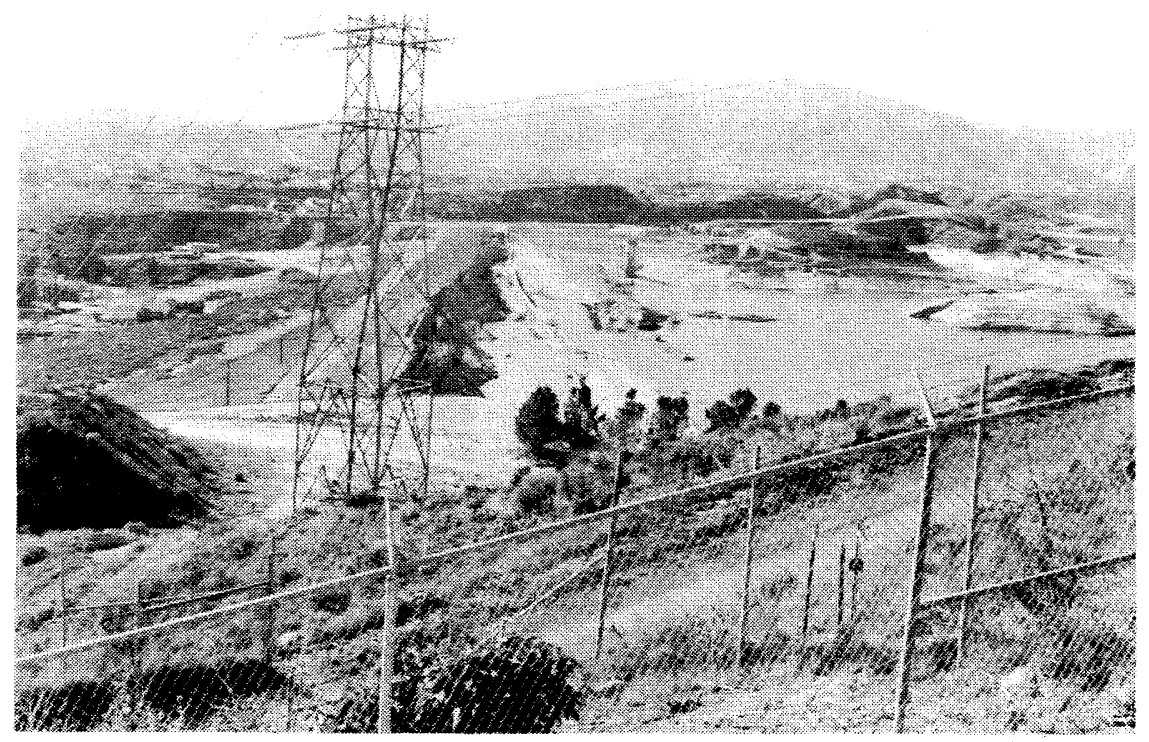

Fig 32: The failure of the Lower San Fernando Dam at the Van Norman Reservoir. The original dam structure at this si te was constructed of hydraulic fill and put into service in 1915 . In subsequent years, layers of dry fill were added to the dam to increase the reservoir capacity and to reduce the downstream slope. At the time of the earthquake the dam was in a drawdown condition. The crest and the upstream slope slid into the reservoir reducing the $20 \mathrm{ft}$ of the freeboard to about $5 \mathrm{ft}$. The photograph was taken about six weeks after the earthquake, and the reservoir level had been lowered. The dam was approximately $140 \mathrm{ft} \mathrm{high}$ and the upstream slope was $2 \frac{1}{2}: 1$. 


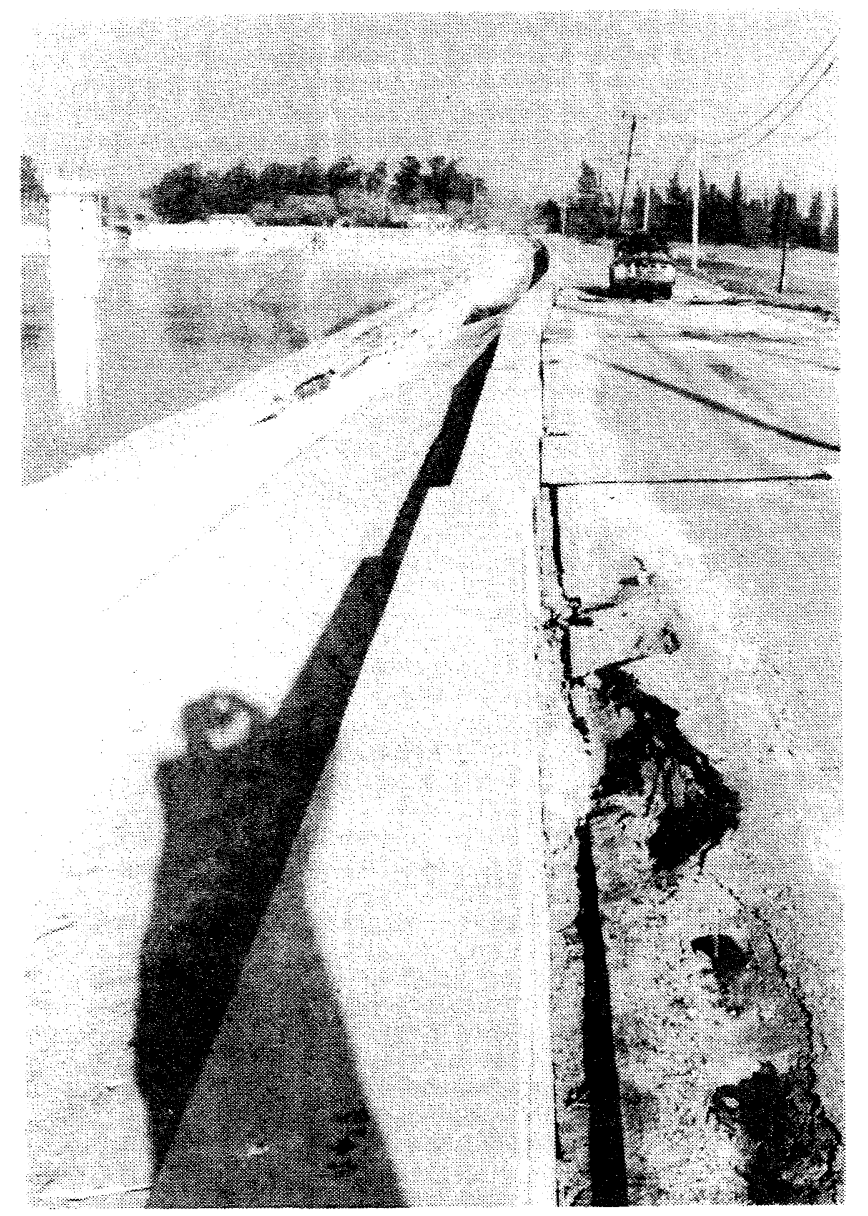

Fig 33: The Upper San Fernando Dam at the Van Norman Reservoir This dam was put into service in 1921 and was constructed of hydraulic fill. The height of the dam was increased by adding a section of dry fill to the crest in subsequent years. The displaced curb blocks show the downstream movement of the dam that reached a maximum displacement of $5 \mathrm{ft}$. The crest of the dam settled approximately $3 \mathrm{ft}$.

Fig 34: A toppled a.c. harmonic filter reactor at the Pacific Intertie electrical switching and rectifying station. This $\$ 110$ million station was not operational at the time of the earthquake, but was to be a vital link in the power distribution system of western United States and Canada. Most of the electrical equipment in the station was damaged.

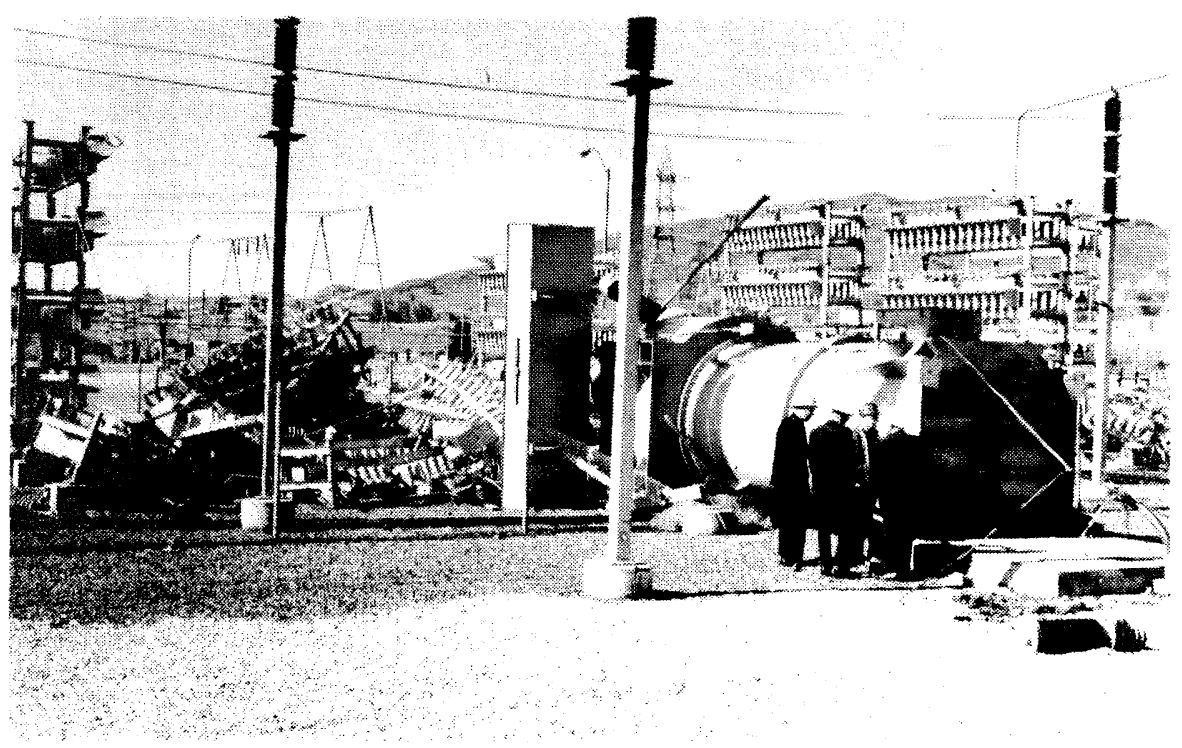


Fig 35: Failure of the suspension cables on a mercury-arc rectifier unit. The cables failed on all the units in the station, dropping the current divider components onto the anodes which were fractured by the impact. Pacific intertie.
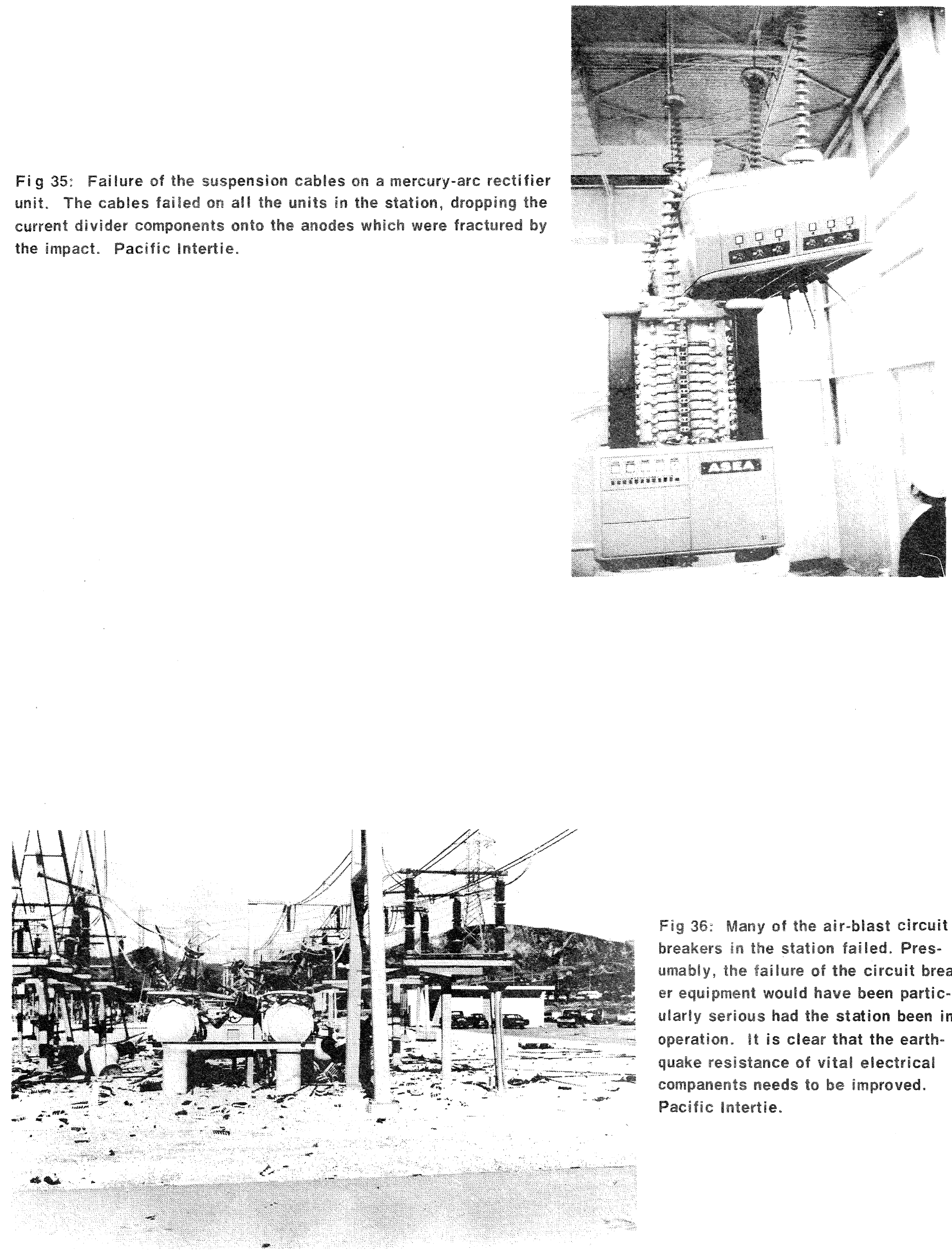

Fig 36: Many of the air-blast circuit breakers in the station failed. Pres. umably, the fallure of the circuit break. er equipment would have been particularly serious had the station been in operation. It is clear that the earthquake resistance of vital electrical companents needs to be improved. Pacific Intertie. 


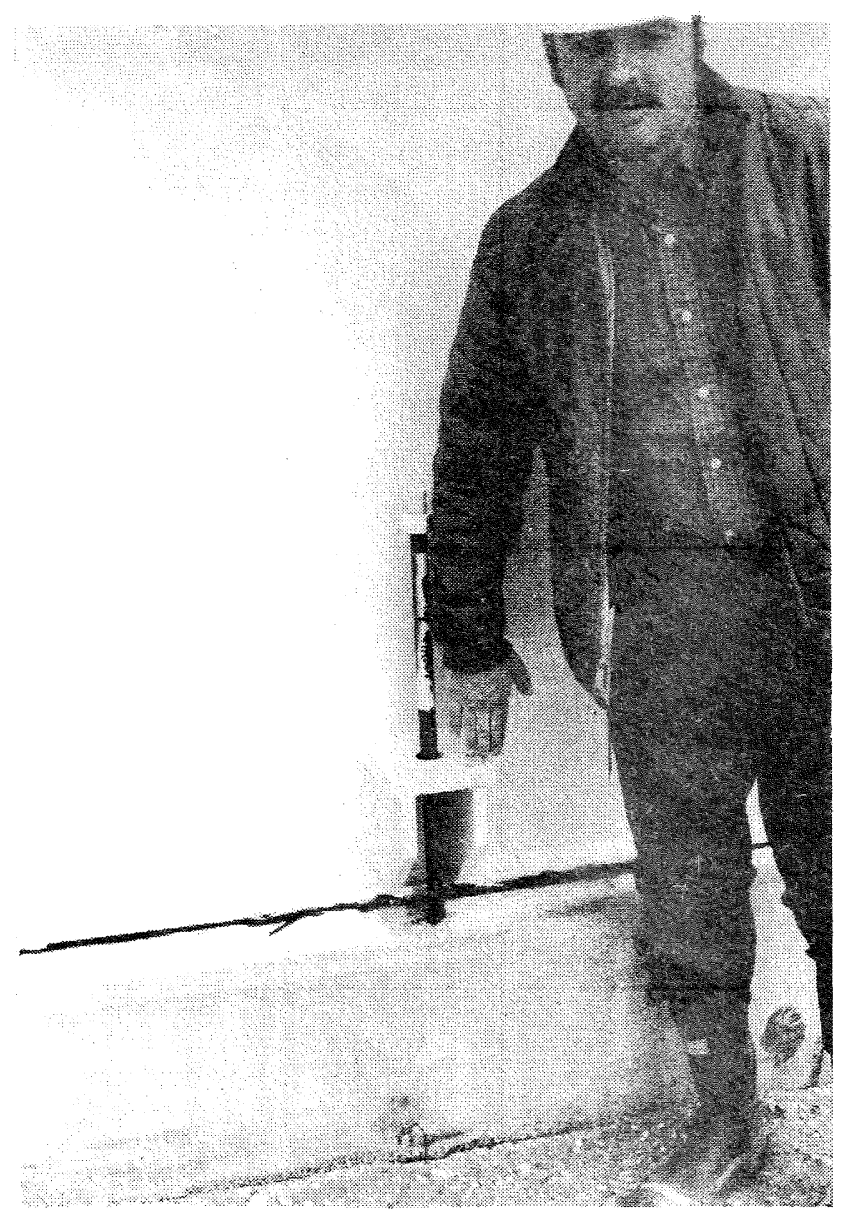

Fig 37: A bond failure of a holding-down bolt on a $100 \mathrm{ft}$ diameter steel tank at the Metropolitan Water District's treatment plant. The steel plates at the top and bottom sections of this tank were buckled. Other serious damage at the plant included the failure of a large concrete underground reservoir.

Fig 38: A buckled and failed section of 16 in-diameter steel gas main. The overthrust type of faulting that caused the earthquake produced a gross shortening of the ground in a number of areas in the San Fernando Valley. This pipeline was probably subjected to severe compression as a result of the faulting. Permanent ground displacements caused extensive disruption to all underground utilities including gas, water, sewer lines and telephone cables.

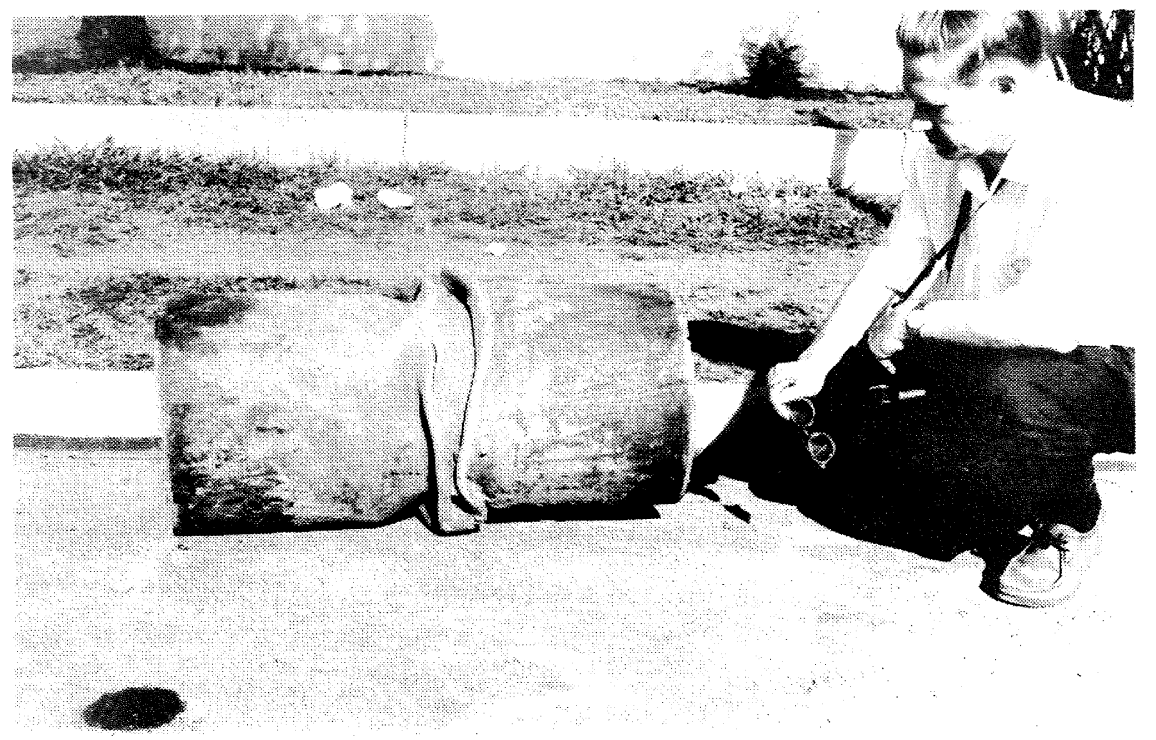

